\title{
Osteoimmunology: memorandum for rheumatologists
}

\author{
Lidan Zhao ${ }^{1 \dagger}$, Linfang Huang ${ }^{2 \dagger}$ \& Xuan Zhang ${ }^{1 *}$ \\ ${ }^{1}$ Department of Rheumatology \& Clinical Immunology, Peking Union Medical College Hospital, Chinese Academy of Medical Sciences and \\ Peking Union Medical College, the Ministry of Education Key Laboratory, Beijing 100730, China; \\ ${ }^{2}$ Department of Rheumatology, the First People's Hospital of Yueyang, Yueyang 414000, China
}

Received April 12, 2016; accepted May 17, 2016; published online September 9, 2016

\begin{abstract}
Rapid progress has been made in exploring the connections between the skeletal system and the immune system over the past decade. Bone tissue forms developmental niches for hematopoietic stem cells, and activated immune cells are involved in bone metabolism regulation and are potent mediators of osteoporosis and bone erosion under pathological conditions. The interdisciplinary field of osteoimmunology has emerged to pool the knowledge of the interdependence of these two systems, including the shared ligands and receptors, their crosstalk and interaction, and common intracellular signaling pathways with bidirectional influence. The receptor activator of nuclear factor-kappa B (RANK)/RANK ligand (RANKL)/osteoprotegerin (OPG) triad is the key vinculum, with multifaceted potency, being not only essential for osteoclastogenesis but also critical for lymph node organogenesis and lymphopoiesis as well as for immune regulation. In this review, we summarize the progress in this area, focusing on those aspects of interest concerning rheumatic diseases.
\end{abstract}

osteoimmunology, bone remodeling, osteoclastogenesis, immune cells, RANKL

Citation: Zhao, L., Huang, L., and Zhang, X. (2016). Osteoimmunology: memorandum for rheumatologists. Sci China Life Sci 59, 1241-1258. doi: 10.1007/s11427-016-5105-7

\section{INTRODUCTION}

Bone is a biologically dynamic entity with permanent cell activity and continuous remodeling, rather than a static, unchanging tissue. Weight bearing, hematogenesis and coordination of calcium homeostasis are the primary roles of bone tissue. However, immune regulation and immunogenesis are also key roles of bone according to updated knowledge about the codependence of the immune system and the skeletal system, as elucidated by osteoimmunology. Osteoblasts (OBs) originate from mesenchymal stem cells (MSC) and contribute to bone resorption, whereas osteoclasts (OCs) originate from hematopoietic precursors belonging to monocyte and macrophage lineages and are responsible for bone formation. Concerted bone synthesis and

$\dagger$ Contributed equally to this work

*Corresponding author (email: zxpumch2003@ sina.com) bone degradation mediate bone turnover, also known as bone remodeling, which helps to maintain bone density and bone architecture. Bone remodeling starts from the embryonic development period and continues throughout the whole lifespan, which is the fundamental adaptive mechanism of bone in coping with biomechanical pressure and bone damage repair. If the dynamic balance of bone remodeling is skewed toward activated bone resorption, bone loss via either osteoporosis (OP) or bone erosion will occur, as observed in rheumatoid arthritis (RA) and other diseases with systemic inflammatory bone loss.

The term "osteoimmunology" was first introduced by Joseph R. Arron and Yongwon Choi in 2000 (Arron and Choi, 2000). This new discipline has helped to demonstrate the concept that the skeletal system and immune system have an intense interaction and should be considered as a functional unit. Ever since 2000, cumulative evidence of the interplay between immune cells and bone metabolism has 
been obtained, and clinically relevant diseases, such as RA, spondyloarthropathy (SPA), postmenopausal OP, and periodontal disease (PD), have been investigated. This review will summarize current understanding in this field and concentrate on those aspects that interest rheumatologists.

\section{BONE METABOLISM}

OBs, OCs and osteocytes collaborate in continuous bone remodeling and bone mass renewal. OCs are specifically tartrate-resistant acid phosphatase (TRAP)-positive, multinucleated giant cells with polarized ruffled borders that are involved in bone absorption. Cathepsin $\mathrm{K}$, integrin $\beta 3$, the calcitonin receptor and matrix metalloprotein 9 (MMP9) are the primary markers of OCs (Greisen et al., 2015), and nuclear factor of activated T-cells 1 (NFATc1) and c-Fos are the essential transcription factors for osteoclastogenesis (Takayanagi, 2005, 2007; Wagner and Eferl, 2005). In contrast, OBs are basophilic, mononuclear polygonal cells that contribute to bone matrix synthesis by secreting osteoid, embedding themselves into the matrix and then transforming into osteocytes during mineralization, thus contributing to new bone formation. Runt-related transcription factor 2 (Runx2) and peroxisome proliferator-activated receptor gamma $(\operatorname{PPAR} \gamma)$ are the specific transcription factors involved in osteoblastogenesis (Komori, 2011). The bone morphogenetic protein (BMP) cascade and $\mathrm{Wnt} / \beta$-catenin signaling are other central players in osteoblastogenesis through stimulation of Runx2, thus contributing to establishing and maintaining peak bone mass (Baron et al., 2006) (Figure 1).

During the physiological bone remodeling process, OCs
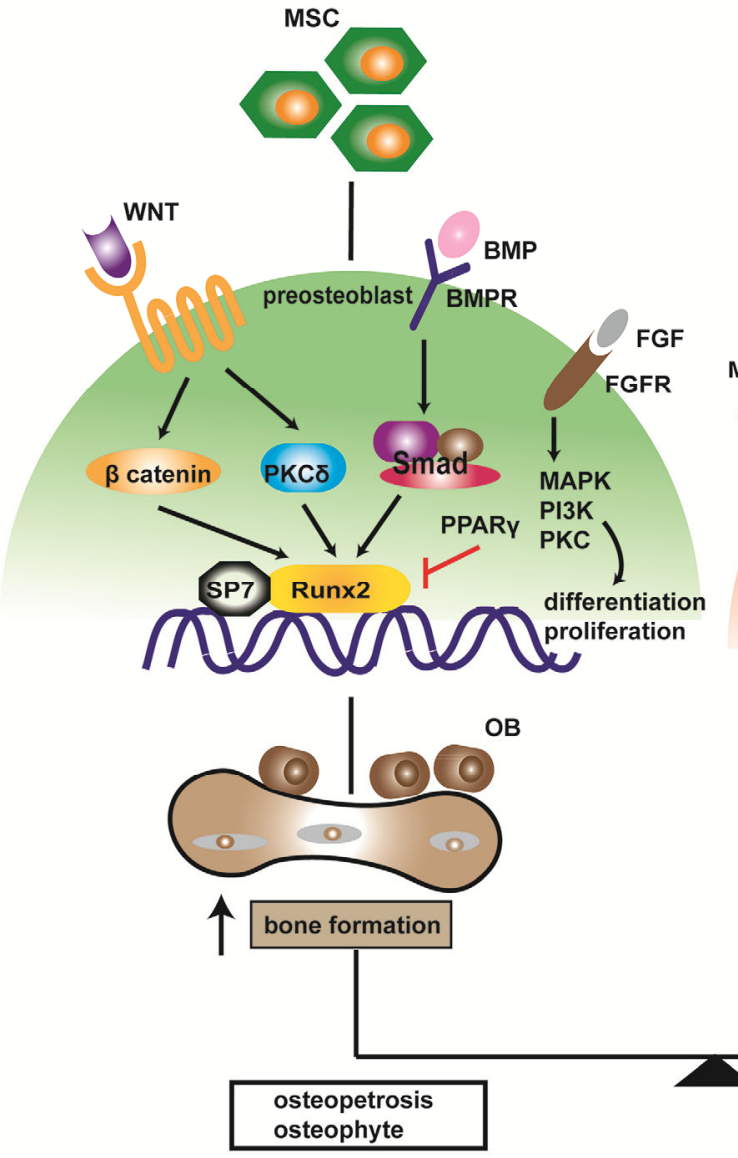

OC precursor
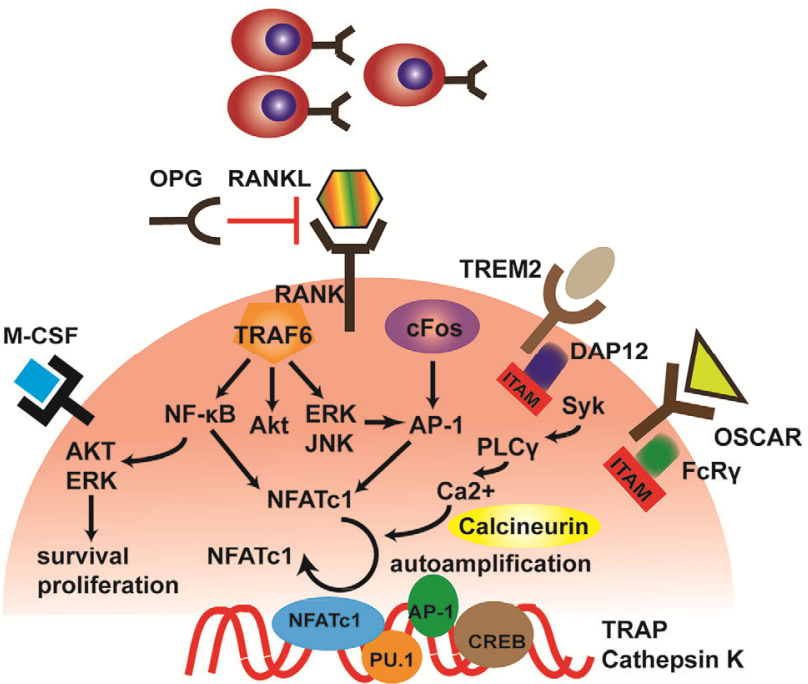

Figure 1 Critical signaling molecules and transcription factors in osteoblastogenesis and osteoclastogenesis. OBs derive from mesenchymal stem cells (MSC) and function as bone formation cells. BMP and Wnt/ $\beta$-catenin are the main signaling pathways contributing to osteoblastogenesis, and Runx 2 is the main transcription factors needed for OB differentiation and maturation and is antagonized by PPAR $\gamma$. Meanwhile, OCs belong to the monocyte and macrophage lineages and function as bone absorption cells, and the RANK-RANKL axis is the central signaling pathway in osteoclastogenesis. TREM2-DAP12 and OSCAR-Fc $\gamma$ R associated with intracellular ITAMs are also involved. The downstream adaptor protein TRAF6 stimulates NFATc1, which is the main transcription factor for osteoclastogenic gene activation. Broken equilibrium of bone formation and bone absorption will lead to pathological bone remodeling. FGF, fibroblast growth factor; BMP, bone morphogenetic protein; BMPR, BMP receptor; MAPK, mitogen-activated protein kinase; PI3K, phosphoinositide 3-kinase; ERK, extracellular regulated kinase; JNK, JUN N-terminal kinase; ITAM, immunoreceptor tyrosine-based activation motif; OSCAR, osteoclast-associated receptor; TREM2, triggering receptor expressed on myeloid cells-2; DAP12, DNAX-activating protein 12; RANK, receptor activator of nuclear factor-kappa B; RANKL, RANK ligand; OPG, osteoprotegerin; TRAF6, tumor necrosis factor receptor-associated factor 6; NFATc1, nuclear factor of activated T-cells 1; PPAR $\gamma$, peroxisome proliferator-activated receptor gamma. 
and OBs are sequentially recruited and activated. Bone resorption is followed by bone formation, composing a coupling of activities that is delicately regulated. Broken equilibrium of the OBs' and OCs' activities leads to abnormal bone remodeling, with increased or decreased bone mass (osteopetrosis or OP, respectively). Several hormones, such as estrogen, parathyroid hormone $(\mathrm{PTH})$, calcitonin and vitamin D3, are involved in bone remodeling. Estrogen exhibits bone-protective effects, as revealed by the occurrence of OP after menopause as well as by disease alleviation during pregnancy and aggravation after delivery in RA patients, which parallel the waxing and waning of estrogen levels. In contrast, the role of PTH in regulating bone remodeling is much more complicated and double edged, with both anabolic and catabolic effects. Intermittent administration of PTH may stimulate OB differentiation and inhibit $\mathrm{OB}$ apoptosis, thus promoting bone formation. Based on this anabolic effect of PTH, the FDA has approved it for OP treatment. However, continuous injection of PTH is reported to facilitate OC formation and to promote bone absorption (Qin et al., 2004). Meanwhile, calcitonin targets activated OCs and inhibits bone resorption, resulting in decreased serum calcium levels and increased bone mineral density (Karsdal et al., 2008). Finally, treatment with vitamin D3 is beneficial for bone biology by increasing bone mineralization and promoting $\mathrm{OB}$ differentiation in vivo, in contrast to its pro-osteoclastogenic effects in vitro (Yoshida and Stern, 2012).

\section{STRUCTURAL AND ANATOMIC CONNECTIONS BETWEEN BONE CELLS AND IMMUNE CELLS}

Cortical bone and cancellous bone constitute the entity of bone tissue. The bone marrow space is loosely compartmentalized and accommodates hematopoietic precursors and trabecular bone. Bone cells and hematopoietic cells share this same microenvironment, with the bone marrow providing a milieu that allows bone cells and hematopoietic precursors to come into close contact and to influence each other. Hematopoietic precursors scatter around the trabecular bone, forming a hematopoietic focus from which immune cells derive. The bone marrow is also the reservoir where memory T/B cells are homing to and where these cells survive for a long time after leaving the secondary lymphoid organs. The nutritive periosteal vasculature provides additional anatomic bases for further communication between the two systems. These vessels penetrate cortical bone, carrying circulatory pro-inflammatory components and assisting $\mathrm{OC}$ precursors homing from the synovium to bone. Endothelial cells and MSC, mature OBs and OCs, osteolineage-derived proteins (e.g., annexin II, angiopoietin I) and cytokines (e.g., interleukin (IL)-10, stem cell factor) participate in constructing the hematopoietic stem cell (HSC) niche, which is a hematopoietic microenvironment that supports survival and self-renewal of HSCs and controls the fate of immune cells (Calvi et al., 2003; Zhang et al., 2003). OBs are thought to be a regulatory component of HSC niches that contribute to hematopoietic progenitor growth and HSC pool maintenance through Notch activation and osteopontin (OPN) secretion (Calvi et al., 2003; Nilsson et al., 2005). CXC chemokine ligand 12 (CXCL12)abundant reticular cells have the potential to differentiate into OBs in mice and are involved in the endosteal niches that regulate HSC maintenance (Sugiyama and Nagasawa, 2012). Annexin-deficient mice have decreased HSC numbers and impaired localization of HSCs to endosteal niches (Jung et al., 2007; Jung et al., 2011). In contrast, the role of OCs in regulating the mobilization of hematopoietic progenitors and modifying HSC niches is controversial. It has been reported that OCs release proteolytic enzymes (e.g., MMP9) to degrade endosteal components and to promote hematopoietic progenitor mobilization into the circulation (Kollet et al., 2006). However, the mobilization of HSCs induced by serial granulocyte colony-stimulating factor (G-CSF) injection is normal in osteopetrotic mice lacking OCs, indicating that OCs are not indispensable for HSC maintenance and mobilization, as previously thought (Miyamoto et al., 2011).

\section{RECIPROCAL INTERACTION BETWEEN IMMUNE SYSTEM AND SKELETAL SYSTEM IMPLICATED FROM ANIMAL MODELS}

Many transcription factors and molecules are shared by the skeletal system and immune system. Genetically modified animal models shed light on the bidirectional influence of these mediators. In mouse models, compromised immune cell development and responses coexist with disturbed bone remodeling (Table 1).

The Pax5 gene encodes B cell lineage-specific activator protein (BSAP), a transcription factor involved in B cell lineage commitment and development below the proB stage (Nutt et al., 1999). Pax $5^{-/-}$mice display arrested B cell development beyond the proB stage, with severe bone loss and increased OC numbers (Horowitz et al., 2004). Pax $5^{-1}$ proB cells lose their B lineage commitment, while owning multilineage potential. Under proper stimulation, $\mathrm{Pax} 5^{-/-}$proB cells can be induced to differentiate into OCs (Nutt et al., 1999). PU.1 is another transcription factor and is required for the development of both the B lineage and the myeloid lineage (McKercher et al., 1999). PU.1 knockout mice exhibit osteopetrosis, along with absence of OCs and macrophages as well as deficiency of B cells, indicating the participation of PU.1 in both osteoclastogenesis and B lymphopoiesis (McKercher et al., 1996; Tondravi et al., 1997). B cell lymphoma 6 (Bcl-6) is required by germinal center B cells to escape from the fate of apoptosis induced by DNA damage; to maintain self-renewal and survival; and to allow 
Table 1 Genetically modified animal models displaying a reciprocal interaction between immune cells and bone remodeling ${ }^{\text {a) }}$

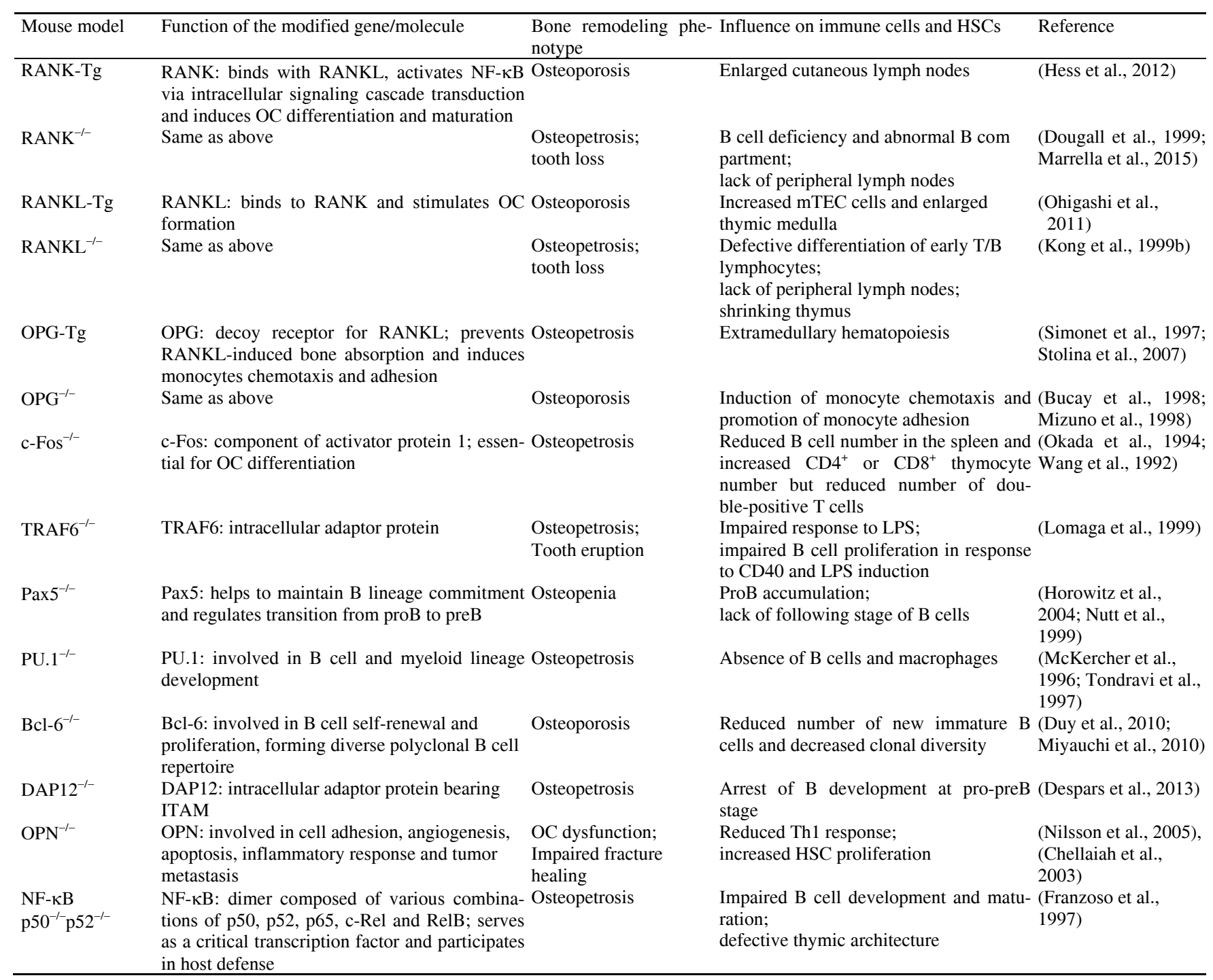

a) HSCs, hematopoietic stem cells; Tg, transgenic; -l-, knockout; RANK, receptor activator of nuclear factor-kappa B; RANKL, RANK ligand; OPG, osteoprotegerin; TRAF6, tumor necrosis factor receptor-associated factor 6; Bcl-6, B cell lymphoma 6; OPN, osteopontin; mTEC, medullary thymic epithelial cell.

formation of a normal, diverse polyclonal repertoire (Duy et al., 2010). Bcl-6 can also facilitate osteoblastogenesis by recuperating the Runx2 nuclear translocation inhibited by STAT1 and can suppress osteoclastogenesis by attenuating NFATc1 target gene transcription (Fujie et al., 2015; Miyauchi et al., 2010). Bcl- $6^{-1-}$ mice exhibit a distinct OP phenotype, with a markedly reduced new immature B cell pool in the bone marrow and impaired clonal diversity (Duy et al., 2010; Miyauchi et al., 2010). Finally, DNAXactivating protein 12 (DAP12) is a transmembrane immunoreceptor tyrosine-based activation motif (ITAM)bearing adaptor protein; ITAM signaling is critical in regulating the innate immune response and adaptive immune cell function as well as OC differentiation. DAP12-deficient mice display interrupted immature B cell development at the pro-preB stage and an impaired immune response, along with a distinct osteopetrosis phenotype (Despars et al., 2013; Hamerman et al., 2005).

\section{RANK/RANKL/OPG triad bridges bone remodel- ing and immune response}

\section{RANK/RANKL/OPG signaling in bone remodeling}

The receptor activator of nuclear factor-kappa B (RANK)/ RANK ligand (RANKL)/osteoprotegerin (OPG) axis is of paramount importance both in physiological bone remodeling and in pathological bone destruction (Theill et al., 2002). This triad is critical in the communication between 
the skeletal system and the immune system.

RANKL, RANK and OPG all belong to the tumor necrosis factor (TNF)/TNF receptor (TNFR) superfamily and were discovered during 1996-1997 (Anderson et al., 1997; Lacey et al., 1998; Nakagawa et al., 1998; Wong et al., 1997a; Yasuda et al., 1998). RANKL, also known as TNFSF11, is reported to be expressed by activated $\mathrm{T}$ cells, $\gamma \delta \mathrm{T}$ cells, B cells and natural killer cells as well as OBs, osteocytes and fibroblasts (Horwood, 2013). Expression of RANK has been reported in macrophages, dendritic cells (DCs), monocytes and OCs. The interaction of RANKL with RANK not only can enhance DC survival and promote cytokine production and T cell-DC interaction but also can contribute to osteoclastogenesis and OC activation; thus, Rankl knockout $\left(\mathrm{Rankl}^{-/}\right)$mice are defective in OC priming and are prone to osteopetrosis (Odgren et al., 2003). People with RANKL gene mutation have been reported to suffer from autosomal recessive osteopetrosis, with function-defective OCs (Sobacchi et al., 2007), whereas transgenic over-expression of RANKL in T cells rescues OC development and restores the bone marrow cavity in $\mathrm{Rankl}^{-1-}$ mice, indicating that $\mathrm{T}$ cells can regulate bone metabolism through the RANKL pathway (Kim et al., 2000). RANK-RANKL signaling is generally accepted as the key pathway responsible for osteoclastogenesis and inflammation-mediated bone destruction. Although how signal transduction following RANK-RANKL conjugation switches on the bone resorption machinery in OCs remains to be elucidated, certain intermediate processes have been proposed.

Macrophage colony-stimulating factor (M-CSF) plays a critical role in inducing OCs proliferation and survival. And via binding to RANK on OCs with surface RANKL, OBs, osteocytes and activated $\mathrm{T}$ cells regulate OCs differentiation and mediate osteoclastogenesis (Xiong et al., 2015). The intracellular domain of RANK contains three cytoplasmic tumor necrosis factor receptor associated factor (TRAF)-binding motifs that can recruit TRAF1, TRAF2, TRAF3, TRAF5, and TRAF6. TRAF6 is particularly essential in mediating RANK-induced nuclear factor-kappa B $(\mathrm{NF}-\kappa \mathrm{B})$ activation and inducing NFATc1 expression (Darnay et al., 1999). The role of NF- $\kappa \mathrm{B}$ in OCs development and bone resorption has been intensely investigated and reviewed (Abu-Amer, 2013). TRAF6 recruitment sequentially induces the activation of downstream signaling cascades, including $\mathrm{NF}-\kappa \mathrm{B}$, c-Fos, extracellular signalregulated kinase (ERK), c-Src, and c-Jun NH2-terminal kinase (JNK) signaling (Wong et al., 1997b), all of which contribute to NFATc1 activation and amplification. The transcription factor NFATc1 is primed to directly regulate the expression of osteoclastogenic genes, including TRAP, cathepsin $\mathrm{K}, \beta$ integrin and the calcitonin receptor, and then promote the differentiation, proliferation, morphogenesis and activation of OCs (Arron and Choi, 2000; Darnay et al., 1998, 1999; Ikeda et al., 2004; Kobayashi et al., 2001; Wong et al., 1999a).

What's more, co-stimulatory immunoglobulin (Ig) like receptors: OSCAR (osteoclast-associated receptor) and TREM2 (triggering receptor expressed on myeloid cells-2) are associated with ITAM-containing adaptor moleculesFc receptor common $\gamma$ unit $(\mathrm{Fc} \gamma \mathrm{R})$ and DAP12 respectively, and RANK activation leads to the phosphorylation of ITAM and then activate calcium ions signaling which also contributes to NFATc1 priming (Takayanagi, 2009).

The interaction of RANK and RANKL can be impeded by the naturally occurring decoy receptor OPG, which is produced by stromal cells, B lymphocytes and DCs. OPG competes with RANK for RANKL binding with a higher affinity and is capable of blocking signal transduction downstream of RANK and inhibiting OC development and activation. OPG can prevent bone loss and act as a bone protector, as its name implies. OPG-transgenic mice exhibit osteopetrosis and decreased OC numbers, along with extramedullary hematopoiesis (Simonet et al., 1997; Stolina et al., 2007). In contrast, OPG-deficient mice show severe OP and are prone to bone fracture (Bucay et al., 1998; Mizuno et al., 1998). As estrogen promotes OPG production by OBs, OP in postmenopausal women develops partly due to reduced estrogen. The RANK/RANKL/OPG triad is the critical vinculum bridging the immune response and bone metabolism. In particular, activated $\mathrm{T}$ cells are capable of inducing morphological maturation and functional activation of OCs and triggering bone absorption through surface RANK. The triad also participates in the cardiovascular, endocrine and nervous systems and plays a critical role in malignant bone metastases, but these topics are outside the focus of this review.

\section{Role of RANK/RANKL/OPG in lymphoid organogenesis and immune response}

RANKL was first cloned in $\mathrm{T}$ cells and is widely accepted to be important in T/B lymphocyte development and DC survival. The RANK-RANKL interaction can promote CD40 expression, and the ligation of CD40 with CD40 ligand (CD40L), which in turn up-regulates OPG expression on follicular DCs (Yun et al., 1998). Coordinating with other cytokines, RANK/RANKL/OPG orchestrates tuning of the immune response by priming $\mathrm{T}$ cell activation, regulating $\mathrm{T}$ cell-DC communication, promoting DC survival and participating in lymph node (LN) organogenesis (Anderson et al., 1997; Wong et al., 1997a).

\section{LN organogenesis}

Comprehensive expression of RANKL on multiple immune tissues, including the LNs, spleen, thymus and intestinal Peyer's patches, suggests its possible influence on secondary lymphoid organ development and organization. 
$\mathrm{RANK}^{-/}$, $\mathrm{RANKL}^{-/}$and $\mathrm{TRAF6}^{-1-}$ mice exhibit completely absent LNs and smaller Peyer's patches but an intact spleen, suggesting a specific and essential role of the RANK/RANKL/OPG triad in LN organogenesis (Dougall et al., 1999; Kong et al., 1999b). It is postulated that RANK-RANKL signaling may act as a growth and survival mediator in the early development of LNs by recruiting lymphopoietic precursors and stimulating the proliferation of stromal cells. When coupled with lymphotoxin (LT)-LT $\beta$ receptor (LTBR) signaling, the RANK-RANKL signal forms an important positive feedback loop between lymphoid tissue organizer (LTo) cells, which are of mesenchymal origin, and lymphoid tissue inducer (LTi) cells, which are of hematopoietic origin (Mueller and Hess, 2012). LTi cells express RANK, RANKL and LT. RANK on LTi cells is triggered by interaction with RANKL-bearing LTi cells and leads to enhanced production of $L T \alpha \beta$. Binding of LT $\alpha \beta$ with its receptor LT $\beta R$ on LTo cells in turn induces more RANKL production (Mueller and Hess, 2012; Roozendaal and Mebius, 2011). This self-amplification feedback results in abundant synthesis of chemokines such as CXCL13 and adhesion molecules such as intracellular adhesion molecule 1 (ICAM-1), vascular adhesion molecule 1 (VCAM-1) and mucosal addressin cell adhesion molecule 1 (MAdCAM-1). These molecules help to attract and retain more LTi cells in the LNs and give rise to functional LN establishment (Koning and Mebius, 2012). Moreover, RANK-transgenic mice display hyperplastic LNs, with proliferated vascular and reticular fibroblastic stromal cells (Hess et al., 2012). Thus, RANK-RANKL signaling contributes to the development of LNs by boosting both lymphopoietic and MSC accumulation.

\section{Innate immune response}

Mice injected with lipopolysaccharide (LPS) show downregulated RANKL and up-regulated OPG. RANKL pretreatment induces macrophage tolerance to bacterial immunization in these mice by suppressing inflammatory cytokine production, protecting the mice from LPS-induced death (Maruyama et al., 2006). For Tnfsf $11^{-1-}$ mice, which lack RANKL, LPS stimulation can potentiate increased release of TNF- $\alpha$ and IL-6, and elevated lethality can be observed. Conversely, Tnfrsf $11 b^{-1-}$ mice, which lack OPG but have a higher serum level of RANKL, exhibit impaired production of IL-6 in response to LPS stimulation (Maruyama et al., 2006). Toll-like receptors (TLRs) have been reported to promote $\mathrm{OC}$ formation by up-regulating RANKL expression on fibroblast-like synoviocytes in RA (Kassem et al., 2015; Kim et al., 2007a, 2009). However, TLRs have also been reported to be capable of inhibiting osteoclastogenesis and limiting the pathological bone loss associated with inflammation through inhibition of RANK expression in cooperation with interferon (IFN)- $\gamma$ (Ji et al., 2009).

\section{Interaction of immune cells and bone cells}

\section{Interaction of $T$ cells and bone cells}

$\mathrm{T}$ cells play a dual role in bone remodeling. Resting $\mathrm{T}$ cells potentiate bone protection, probably by inducing OPG production via CD40L costimulation. T cell-depleted mice experience decreased bone density and increased OC numbers (Li et al., 2007). Meanwhile, activated T cells up-regulate surface RANKL expression to enhance OC development and participate in inflammation-associated OP (Kong et al., 1999a). A protective self-induced countermeasure mechanism against activated $\mathrm{T}$ cells mediated osteoclastogenesis under physiological conditions has been proposed by Takayanagi et al. (Takayanagi et al., 2000). They discovered that IFN- $\gamma$ secreted by inflammatory $\mathrm{T}$ cells is capable of activating the ubiquitin-proteasome pathway and leading to rapid TRAF6 degradation. This counterbalances enhanced RANKL expression and suppresses OC development. Ifnr ${ }^{-1}$ mice develop accelerated bone destruction compared with wild-type mice when experiencing collagen-induced inflammatory arthritis, which provides further evidence for this protective mechanism. Not all activated T cells are osteoclastogenesis promoters. Th1 and Th2 cells are reported to inhibit osteoclastogenesis by secreting IFN- $\gamma$ and IL-4, whereas Th17 cells facilitate osteoclastogenesis through their own surface RANKL expression and IL-17-mediated RANKL expression on supporting cells (Sato et al., 2006). By recruiting other inflammatory cells and promoting the release of inflammatory cytokines such as TNF- $\alpha$ and IL-1, Th17 cells polarize the microenvironment in favor of OC development. $I l 17^{-1-}$ mice of arthritis model and mice with collagen-induced arthritis (CIA) that are injected with a neutralizing antibody against IL-17 are protected from bone destruction (Lubberts et al., 2004; Nakae et al., 2003). In addition, IL-17F released by Th17 cells during bone fracture is a pivotal cytokine in promoting $\mathrm{OB}$ maturation and bone healing (Nam et al., 2012). Other cytokines released from $\mathrm{T}$ cells during inflammation may be able to interfere with OC formation, e.g., IL-12 alone or in synergy with IL-18 can potently inhibit RANKL-induced OC formation in vitro, probably by driving Th1 development and IFN- $\gamma$ signaling (Horwood et al., 2001).

Although poorly defined and lacking sufficient evidence, $\mathrm{T}$ cells may play a role in osteoblastogenesis by coupled up-regulated bone turnover. Rifas et al. deduced that increased alkaline phosphatase activity in bone marrow stromal cells (BMSCs) and elevated mRNA expression of Runx 2 and osteocalcin by soluble factors released from $\mathrm{T}$ cells indicate the capacity of $\mathrm{T}$ cells in inducing OB differentiation (Rifas et al., 2003). Regulatory T cells (Treg) have been shown to be capable of directly affecting bone biology and effectively preventing the local bone destruction and systemic bone loss induced by TNF- $\alpha$ (Zaiss et al., 2010a). Foxp3-transgenic mice are protected from ovariectomy- 
induced OP via impaired OC differentiation (Zaiss et al., 2010b), and activated Treg transfer has been reported to improve the clinical outcome in CIA mice and to inhibit OC differentiation both in vitro and in vivo (Kelchtermans et al., 2009). It is supposed that Treg suppress osteoclastogenesis by cell-cell contact via cytotoxic T-lymphocyte antigen 4 (CTLA4) and by secretion of transforming growth factor (TGF)- $\beta$, IL-4 and IL-10 (Kim et al., 2007b; Zaiss et al., 2007). Yet it's worthy of notice that Treg cells possess plasticity and pathogenic Th17 cells could originate from Treg. Those IL- $17^{+}$Foxp $3^{+} \mathrm{T}$ cells are found accumulating in the synovium of inflamed joints of patients with RA and are thought as potent osteoclastogenic and arthritogenic $\mathrm{T}$ cells expressing RANKL. Contrary to the anti-inflammatory effect of classic Treg, IL- $17^{+}$Foxp $3^{+} \mathrm{T}$ cells are "inflammatory Treg" which may be the product of imbalanced cytokines status and intense contest between autoimmunity and self-tolerance (Komatsu et al., 2014). Anyway, anti-TNF- $\alpha$ therapy can restore Treg function via increased Foxp3 phosphorylation and adjust the balance between Treg and Th17 cells (Nie et al., 2013), to which its effectiveness in RA can be partly owing. Modulating Treg development and increasing Treg numbers may therefore be a promising therapeutic strategy in diseases associated with overactivated OCs and accelerated bone loss.

The RANK/RANKL/OPG triad is of great importance in $\mathrm{T}$ cell development. T cell negative selection and Foxp $3^{+}$ Treg emergence in the thymus are dependent on the medullary thymic epithelial cell (mTEC) compartment and the thymic medullary microenvironment (Aschenbrenner et al., 2007; Hikosaka et al., 2008; Ohigashi et al., 2011). mTECs present self-antigens, participate in establishing $\mathrm{T}$ cell central tolerance checkpoints and contribute to autoreactive $\mathrm{T}$ cell clonal deletion in the thymus. RANK, OPG, CD40, and LT $\beta R$ expressed on mTECs cooperate to promote mTEC development and help to establish and maintain the homeostasis of the thymic medullary microenvironment (Akiyama et al., 2008). Rankl ${ }^{-1-}$ mice exhibit blocked differentiation from $\mathrm{CD} 25^{+} \mathrm{CD} 44^{-}$to $\mathrm{CD} 25^{-} \mathrm{CD} 44^{-}$thymocytes and reduced thymic cellularity (Kong et al., 1999b). Similar progression defects can also be observed in OPG-transgenic mice and recombinant-OPG-treated mice (Stolina et al., 2007).Th1 cytokines produced by $\mathrm{rankl}^{-1-} \mathrm{T}$ cells are significantly reduced under stimulation with anti-CD3/antiCD28 and cannot be restored by exogenous RANKL (Kong et al., 1999b). In contrast, RANKL-transgenic mice display increased mTEC numbers and an enlarged thymic medulla, indicating the regulatory function of the RANK-RANKOPG signal in the early development of $\mathrm{T}$ cells. RANKL signaling in the thymus influences the intrathymic Treg pool by enhancing peripheral Treg recirculation back to the thymus (McCarthy et al., 2015). OCs have been reported to be capable of inducing $\gamma \delta \mathrm{T}$ cell activation and proliferation as well as supporting $\gamma \delta \mathrm{T}$ cell survival in vitro, mainly through a TNF- $\alpha$-mediated pathway or direct cell-cell contact (Pappalardo and Thompson, 2015). Conversely, activated $\gamma \delta \mathrm{T}$ cells negatively regulate $\mathrm{OC}$ formation by secreting IFN- $\gamma$ (Pappalardo and Thompson, 2013).

\section{Interaction of $B$ cells and bone cells}

The $\mathrm{B}$ cell lineage has a profound reciprocal interaction with the bone system (Manilay and Zouali, 2014). B cell-produced OPG has been proven to be an important regulator in bone metabolism ( $\mathrm{Li}$ et al., 2007), and this production can be augmented by T cells via CD40-CD40L costimulation (Yun et al., 1998). B cell depletion in mice leads to significantly decreased OPG and increased bone resorption, which can be rescued by $\mathrm{B}$ cell reconstitution. This finding is of certain physiopathological importance in protecting bone against damage when confronted with infection and inflammation. Meanwhile, B cells are also a source of RANKL, thus playing a role in shaping OC development. Under certain pathological conditions, RANKL produced by B cells may neutralize or overwhelm B cell-derived OPG, resulting in accelerated bone loss. In vitro, activated B cells can promote the development and maturation of OCs by producing multiple cytokines (Choi et al., 2001). The IgG immune complex (IgG-IC) comprehensively regulates the immune response through $\mathrm{Fc} \gamma \mathrm{R}$ signaling, but meanwhile is also a potent stimulator of OC formation. High titers of IgG in CIA mice strongly promote osteoclastogenesis, which can be abrogated by depleting IgG in the serum. Negishi-Koga et al. have recently reported that the engagement of Fc $\gamma$ Rs provides costimulatory signals for osteoclastogenesis (Negishi-Koga et al., 2015). IgG-ICFc $\gamma \mathrm{R}$ signaling participates in OC expansion and bone homeostasis breakdown. Fc $\gamma$ RIIB and Fc $\gamma$ RIII are negative modulators of osteoclastogenesis, with a mechanism of competitive occupation, depleting the availability of Fc $\gamma \mathrm{R}$ to other activating ligands. Temporary down-regulation of Fc $\gamma$ RIII is a necessary physiological process during OC differentiation (Negishi-Koga et al., 2015). Harre et al. further verified that desialylated IgG-ICs with enhanced binding and engagement of Fc $\gamma$ Rs could be more favorable for driving osteoclastogenesis (Harre et al., 2015).

$\mathrm{B}$ cell commitment and maturation are dependent on cell-cell contact with OBs (Zhu et al., 2007), while OCs can support the survival of plasma cells independent of B lymphocyte stimulation through cell-cell contact (GeffroyLuseau et al., 2008). Absence of preB and proB cells in Col2.3 $\Delta$-TK-transgenic mice after selective depletion of OBs confirmed the role of OBs in B cell lymphopoiesis (Zhu et al., 2007). OB-derived RANKL is essential for preB cells to develop into mature B cells, and pre-B cells exhibit arrested development in $\mathrm{rankl}^{-1-}$ mice (Zhu et al., 2007). But the role of the RANK-RANKL axis in B cell physiology is far more sophisticated and still a matter of debate. Recently, $r a n k l^{-1-}$ mice are found to exhibit relative expansion of 
marginal zone B cells and plasma cells, increased Ig secretion and spontaneous germinal center formation, which may be attributed to increased regulatory $B$ cell numbers and enhanced IL-10 production (Marrella et al., 2015). Both OBs and multipotent stromal cells are the main sources of stromal cell-derived factor 1 (SDF-1), IL-7 and CXCL12, which collaborate to construct indispensable niches for B cell development (Woodward, 2010; Wu et al., 2008; Zhu et al., 2007). $\mathrm{OPG}^{-1-}$ mice have been reported to have accumulated transitional B cells in the spleen, enhanced B cell proliferation under IL-7 stimulation, and compromised Ig switching in response to T cell-dependent antigen (Yun et al., 2001). Paradoxically, OPG-transgenic mice exhibit no significant functional alterations in humoral immune responses (Stolina et al., 2007). However, elimination of functional RANKL or RANK reveals dramatically defective $B$ cell development and hypogammaglobulinemia both in mice and in humans, which may mainly be due to osteopetrosis and a shrinking bone marrow cavity (Guerrini et al., 2008; Kong et al., 1999b).

\section{Interaction of DCs and bone cells}

DCs are highly differentiated antigen-presenting cells with the plasticity to transdifferentiate into OCs under appropriate stimulation (e.g., in the presence of M-CSF and RANKL) (Alnaeeli et al., 2006; Rivollier et al., 2004). RANKL is capable of protecting DCs from Fas ligand-induced apoptosis (Chen et al., 2004). The synergy of RANKL and CD40L, which are both expressed by activated $\mathrm{T}$ cells, controls DC survival and stimulates proinflammatory cytokine production by DCs (Josien et al., 1999, 2000). Similar features can be observed in $\mathrm{OPG}^{-/-}$mice (Chino et al., 2009; Wong et al., 1999b). RA provides a microenvironment in the synovium and synovial fluid that is abundant in pro-inflammatory cytokines capable of supporting transdifferentiation. DC-derived OCs have been suggested to be involved in osteolytic lesions (Santiago-Schwarz et al., 2001). DCs can also act as OB precursors, and T cell-DC interaction may directly contribute (Alnaeeli et al., 2006) to osteoclastogenesis in a RANKL-dependent manner (Page and Miossec, 2005). Considering the important role of DCs in immune response initiation and perpetuation as well as their status as efficient inducers of Th17 cells (Dhodapkar et al., 2008), DCs are important mediators of inflammation-associated bone loss and provide a promising therapeutic target for modulating inflammatory bone destruction (Alnaeeli et al., 2007).

\section{Role of cytokines in bone homeostasis}

Multiple cytokines and factors are involved in the complex bone homeostasis regulatory network, especially during rheumatic bone erosion, which has been reviewed in literature (Arboleya and Castaneda, 2013) and is also summarized in Table 2 .

\section{$M-C S F$}

$\mathrm{M}-\mathrm{CSF}$ is a critical growth stimulator for the macrophage lineage and OC progenitors. In the spontaneous-mutant osteopetrotic mouse strain op/op, decreased OC numbers coupled with impaired bone resorption and defective M-CSF production are key characteristics (Felix et al., 1990b). Op/op mice are specifically deficient in M-CSF and exhibit osteopetrosis. Replenishment with recombinant M-CSF can induce OC formation and restore the bone marrow cavity that is absent in op/op mice (Felix et al., 1990a). M-CSF stimulates RANK expression in OC precursors, promotes OC differentiation and prolongs OC survival in vivo (Fuller et al., 1993) and is indispensable for inducing OC formation from monocytes/macrophages in vitro (Marino et al., 2014).

\section{$T N F-\alpha$}

TNF- $\alpha$ can enhance RANKL expression on OBs and $\mathrm{M}-\mathrm{CSF}$ production by stromal cells, can augment the responsiveness of OC precursors to RANKL and can stimulate OC maturation. Moreover, TNF- $\alpha$ can induce the expression of OSCAR, which in turn costimulates OC formation. By modulating Wnt signaling activation, inhibiting the expression of the transcription factor Runx2 and up-regulating the RANKL/OPG ratio, TNF- $\alpha$ suppresses OB differentiation while promoting OC maturation. In the presence of M-CSF, TNF- $\alpha$ coupling with IL- 1 can induce mouse bone marrow macrophages to develop into TRAR $^{+}$ OCs (Yamashita et al., 2015; Zhang et al., 2001). Flourishing clinical application of TNF- $\alpha$ blockers in RA and other types of inflammatory arthritis has yielded inspiring therapeutic effects in preventing progressive bone destruction, even reversing bone erosion.

\section{IL-1}

IL-1 is another potent osteoclastogenesis inducer produced by macrophages, MSC and lymphocytes. IL-1 is capable of up-regulating RANKL expression on BMSCs and inducing OC precursors to differentiate into mature OCs as well as prolonging OC survival and enhancing OC bone-absorbing activity. TNF- $\alpha$ can induce IL-1 production, coordinate with IL-1 and depend on IL-1 to mediate OC activation and promote inflammation-associated bone loss (Wei et al., 2005). Bone loss induced by estrogen deficiency occurs partly via IL-1, and blockade of IL-1 can prevent bone loss both in postmenopausal women and in ovariectomized mice.

\section{$I F N-\gamma$}

IFN- $\gamma$ abrogates the signaling transduction downstream of RANKL and rescues OP in ovariectomized mice (Duque et al., 2011; Takayanagi et al., 2000). IFN- $\gamma$ also plays a role in osteoblastogenesis by promoting the differentiation of MSC into OBs (Duque et al., 2009). And by mediating 
Table 2 Cytokines involved in bone remodeling and the immune response $\mathrm{e}^{\text {a) }}$

\begin{tabular}{|c|c|c|c|}
\hline Cytokine & Source & Effect on $\mathrm{OBs} / \mathrm{OCs}$ & Effect on immunity \\
\hline TNF- $\alpha$ & Th1, macrophage, DC & $\begin{array}{c}\text { OB formation } \downarrow / \uparrow ; \\
\text { OC formation } \uparrow ; \\
\text { OB formation } \uparrow ;\end{array}$ & Pro-inflammation \\
\hline IFN- $\gamma$ & Th1, natural killer cell & $\begin{array}{l}\text { OC formation } \downarrow / \uparrow \\
\text { (depends on context) }\end{array}$ & Cellular immunity \\
\hline IL-12 & Macrophage, DC & OC formation $\downarrow$ & $\begin{array}{l}\text { Th1 cell differentiation; } \\
\text { IFN- } \gamma \text { and GM-CSF induction }\end{array}$ \\
\hline IL-18 & Macrophage, DC & OC formation $\downarrow$ & Th1 cell differentiation, IFN- $\gamma$ induction \\
\hline GM-CSF & Th1 & OC formation $\downarrow$ & Macrophage recruitment; pro-inflammation \\
\hline IL-4 & Th2 & OC formation $\downarrow$ & Humoral immunity \\
\hline IL-6 & $\begin{array}{l}\text { Macrophage, DC, } \\
\text { Th2 synovial fibroblast }\end{array}$ & OC formation $\uparrow$ & Pro-inflammation; Th17 induction \\
\hline IL-10 & Th2, Treg & OC formation $\downarrow$ & Anti-inflammation \\
\hline IL-17 & Th17, $\gamma \delta \mathrm{T}$ & $\begin{array}{l}\text { OB formation } \downarrow ; \\
\text { OC formation } \uparrow\end{array}$ & Pro-inflammation \\
\hline IL-23 & Macrophage, DC & OC formation $\uparrow$ & Th17 induction \\
\hline IL-1 & Macrophage, DC & OC formation $\uparrow$ & Pro-inflammation \\
\hline TGF- $\beta$ & Treg, OB, BMSC & OC apoptosis $\uparrow$ & $\begin{array}{l}\text { Anti-inflammation, involved in Th17/Treg dif- } \\
\text { ferentiation }\end{array}$ \\
\hline OSM & OB, OC, macrophage, $\mathrm{T}$ cell & $\begin{array}{c}\text { OB formation and mineralization } \uparrow ; \\
\text { OC formation } \uparrow \\
\text { (pathological condition) }\end{array}$ & Induction of megakaryocyte hematopoiesis \\
\hline IL-7 & BMSC & OC formation $\uparrow$ & Promotion of T/B cell development \\
\hline IL-27 & Macrophage, DC & OC formation $\downarrow$ & Th1 and Treg $\uparrow ;$ Th17 induction \\
\hline
\end{tabular}

a) DCs, dendritic cells; OSM, oncostatin M. Treg, regulatory T cell; Th17, IL-17 secreting T cell; BMSC, bone marrow stromal cell

rapid TRAF6 degradation via activating ubiquitinproteasome, IFN- $\gamma$ suppresses OC development and acting as a bone-protective factor. But IFN- $\gamma$ can also act as a pro-absorptive cytokine by stimulating antigen-dependent $\mathrm{T}$ activation and promoting T cell secretion of TNF- $\alpha$ and RANKL (Gao et al., 2007). Therefore, the paradoxical role of IFN- $\gamma$ in bone remodeling involves directly targeting OC precursors to inhibit osteoclastogenesis and indirectly stimulating OC formation to facilitate osteoclastogenesis. The influence of IFN- $\gamma$ on bone homeostasis is dependent on the net effects in different contexts.

\section{$I L-4$}

IL-4 is a pleiotropic cytokine that has also been found to be a potent negative regulator of $\mathrm{OC}$ formation and $\mathrm{OC}$ activation through inhibiting NFATc1 and c-Fos expression, inducing OPG production and attenuating RANKL and RANK expression via a mechanism depending on STAT6-mediated NF-кB signaling inhibition (Abu-Amer, 2001; Moreno et al., 2003; Palmqvist et al., 2006; Yamada et al., 2007).

\section{IL-10}

In bone remodeling, synthesis of bone proteins (e.g., alkaline phosphatase, collagen and osteocalcin) and mineralization of extracellular matrix can be suppressed by IL-10. Additionally, by inhibiting the intranuclear translocation of NFATc1, IL-10 can prevent RANKL-mediated osteoclas- togenesis at an early stage (Evans and Fox, 2007; Mohamed et al., 2007). IL-10 $0^{-/-}$mice thus develop an osteopenic phenotype with increased bone fragility (Dresner-Pollak et al., 2004).

\section{IL-6}

IL-6, produced by macrophages, DCs and BMSCs, is a potent stimulator of $\mathrm{OC}$ activation and bone absorption via RANKL up-regulation. In synergy with TNF- $\alpha$, IL-6 plays a pivotal role in the synovitis with pannus formation and contributes to the pathogenesis of RA. Blockade of IL-6 ameliorates the osteoclastogenesis induced by active RA sera in vitro (Pathak et al., 2014) and suppresses joint destruction in FcrRIIB-deficient RA mice (Ohtsuji et al., 2015).

\section{IL-17}

Th17 cells are IL-17-secreting cells with robust RANKL expression and vigorous pro-inflammatory potency (Takayanagi, 2009). IL-17 has been shown to synergistically induce RANK expression on OC precursors and promote RANKL expression on OBs, BMSCs and synovial fibroblasts, thus supporting OC development (Adamopoulos and Bowman, 2008; Adamopoulos et al., 2010). IL-17 is also thought to play a critical role in progressive periodontitis (PD) and erosive arthritis. Neutralizing IL-17 in CIA mice therefore helps to reduce joint inflammation, cartilage destruction and bone erosion. 
$T G F-\beta$

TGF- $\beta$ positively modulates bone formation by inducing OB precursor differentiation and migration and abrogating OB apoptosis, possibly by enhancing Runx2 expression (Lee et al., 2000). However, in the later stage of OB maturation, TGF- $\beta 1$ inhibits the proliferation and mineralization of OBs in accordance with Runx2 suppression (Alliston et al., 2001; Kang et al., 2005).

\section{Oncostatin M(OSM)}

OSM is a pleiotropic cytokine belonging to the IL-6 family that influences both bone formation and bone resorption. Irrespective of its role in malignancy, OSM, produced by cells of hematopoietic origin (e.g., $\mathrm{T}$ lymphocytes and macrophages) and mesenchymal origin (e.g., OBs and osteocytes) in the bone marrow microenvironment, can control both OB and OC formation. In particular, OSM promotes $\mathrm{OB}$ differentiation and directs stromal cells to $\mathrm{OB}$ commitment. OSM is also capable of inducing RANKL expression on OBs to drive osteoclastogenesis and has the potential to contribute to bone destruction in inflammatory arthritis and bone metastasis in combination with IL-1 and TNF- $\alpha$ (Bolin et al., 2012; Hui et al., 2005; Le Goff et al., 2014). Therefore, OSM exerts both anabolic and catabolic effects on bones and participates in pathological bone destruction and new periosteal bone formation.

\section{$O P N$}

OPN is a cytokine with pleiotropic properties that is synthesized by multiple cell types, including immune cells such as DCs and T/B lymphocytes and bone cells such as OBs. OPN plays a role in bone remodeling, modulates mineralization of the skeleton and participates in absorption of mineralized bone by anchoring OCs onto the bone surface and stimulating interaction of OCs and stromal cells (Denhardt et al., 2001; Heinegard et al., 1995). OPN is also involved in regulating the immune response to injury; infection; and auto-inflammatory disease, such as RA, via integrins and CD44 (Xu et al., 2005). Although not indispensable, OPN modulates cell-mediated responses by promoting the Th1 response, as indicated by an abrogated Th1 response in $\mathrm{OPN}^{-1-}$ mice, and is also capable of supporting Th17 and B cell differentiation (Rittling and Singh, 2015) as well as influencing IFN- $\gamma$, IL-10 and IL-12 production (Ashkar et al., 2000).

\section{Complement}

The complement system serves as an important component of innate immunity by opsonizing antigens, mediating phagocytosis, modulating cell migration and apoptosis, inducing cytokine release and promoting the inflammatory reaction, thus playing a critical role in defense against invasive microorganisms and in clearance of cellular debris of self-origin (Zipfel and Skerka, 2009). Evidence shows that the complement system also plays a role in bone biology. For example, modulation of complement C3a and C5a have been reported to modulate $\mathrm{OB}$ formation and $\mathrm{OC}$ activation (Ignatius et al., 2011), and reduction of C3aR/C5aR activity inhibits OC generation ( $\mathrm{Tu}$ et al., 2010). In addition, OC-derived C3a stimulates OB differentiation (Matsuoka et al., 2014). In synergy with IL-1 $\beta$, under pro-inflammatory conditions, C3a and C5a are capable of inducing IL-6 and IL-8 release from OBs and up-regulating RANKL/OPG expression, culminating in the inflammatory phenotype of OBs (Ignatius et al., 2011), which represents bidirectional communication between OCs and OBs.

\section{CLINICAL DISEASES ASSOCIATED WITH OSTEOIMMUNOLOGY}

\section{RA (rheumatoid arthritis)}

RA is a typical disorder for demonstrating the connotations of osteoimmunology. Specifically, RA is an autoimmune-mediated chronic inflammatory arthritis with high morbidity and a high rate of crippling. Synovial pannus, juxta-articular osteopenia, and erosion of the cartilage and subchondral bone are the pathological characteristics of RA. Increased levels of activated OCs are the predominant disturbance of bone homeostasis that occurs, and exaggerated levels of pro-inflammatory cytokines, including IL-1, TNF and IL-6, are remarkable both in affected joints and in the peripheral serum (Le Goff et al., 2013). Augmented RANKL expression in RA synovium by synovial fibroblasts and activated $\mathrm{T}$ cells has also been found (Gravallese et al., 2000). It has been confirmed that synovial fluid mononuclear cells in flamed joints have the potential to spontaneously develop into functional OCs ex vivo, which is further augmented in the presence of RANKL and M-CSF (Greisen et al., 2015). Bone loss and erosion in RA are mainly attributed to enhanced RANKL expression on activated synovial fibroblasts; infiltrative mononuclear cells; and activated $\mathrm{T}$ cells, and especially Th17 cells from RA tissue. The concentration of soluble RANKL, which is probably derived from $T$ cells, is comparatively higher than that of OPG in the synovial fluid in RA patients (Kotake et al., 2001). RANKL-loaded activated T cells can directly trigger osteoclastogenesis, leading to OC amplification and bone loss. However, this pro-osteoclastogenic effect may be partly counterbalanced by IFN- $\gamma$ secreted by activated $\mathrm{T}$ cells themselves. Peripheral blood monocytes and synovial macrophages have the potentiality of differentiating into OCs in certain microenvironments (e.g., in the presence of M-CSF and 1,25(OH)2 vitamin D3) (Fujikawa et al., 1996a, b; Takayanagi et al., 1997), which may serve as a critical mechanism of bone destruction in RA. In a mouse model, OPG treatment at disease onset could abolish bone matrix degeneration, inhibit OCs accumulation and prevent cartilage destruction and joint crippling (Kong et al., 1999a). 
The crucial role of cytokines central to the pathogenesis of RA has been reviewed in detail in the literature (McInnes and Schett, 2007).

Anti-citrullinated peptide antibody (ACPA) is a disease-specific antibody with potent pathogenicity for RA via its pro-osteoclastogenic effect. During OC differentiation, specific N-terminal vimentin citrullination is induced. ACPAs can bind to the OC surface, leading to TNF- $\alpha$ release from $\mathrm{OC}$ precursors and stimulating robust osteoclastogenesis and bone absorptive activity (Harre et al., 2012). High titers of ACPAs are strongly associated with early onset and rapid progression of bone lesions. As mentioned before, the pro-osteoclastogenic potency of IgG-ICs is greatly determined by their sialylation levels, in that higher sialylation of the IgG-Fc glycon inhibits OC activation. ACPAs are found to be sialylated at a much lower level than random IgG, which is in accordance with the potency of ACPAs in bone damage. Artificially enhancing the sialylation levels of ACPA in vitro abolishes its activity in driving OC maturation, which may act as a new strategy to treat human RA in the future. In fact, experiments in a CIA mouse model treated with ManNAc, a sialic acid precursor capable of increasing protein sialylation levels, has displayed promising efficacy (Harre et al., 2015). Activated B cells in RA not only produce antibodies (e.g., ACPAs) and secrete inflammatory cytokines but also express RANKL, all of which favor OC differentiation. Thus, the bone-protective efficacy of rituximab by depletion of B cells can be explained and expected (Dohn et al., 2009).

The concept of osteoimmunology strengthens our understanding of the biologic agents that have now been widely used in RA therapy and provides potential targets for new strategies. Except for B cell depletion, cytokine inhibition, including via TNF inhibitors (etanercept, infliximab, adalimumab and golimumab) and IL-6 receptor blockade (tocilizumab), has been confirmed to be clinically effective in retarding the progression of the bone erosion process. CTLA4 switches off the costimulatory CD28:CD80/86 interaction and provides a negative regulatory signal for $\mathrm{OC}$ differentiation (Axmann et al., 2008). CTLA4-Ig (abatacept) introduction into the therapy for active RA has also been proven to be effective (Schiff, 2011), and the mechanism is multifaceted, beyond $\mathrm{T}$ cell costimulation and activation (Cutolo et al., 2016) (Figure 2).

\section{OP (osteoporosis)}

Postmenopausal OP and glucocorticoid (GC)-induced OP (GIOP) are the main types of OP that rheumatologists usually encounter in routine practice. Decreased estrogen in the circulation after menopause will lead to OP, with bone resorption outpacing bone formation. GCs are the indispensable cornerstone of the management of autoimmune disease,

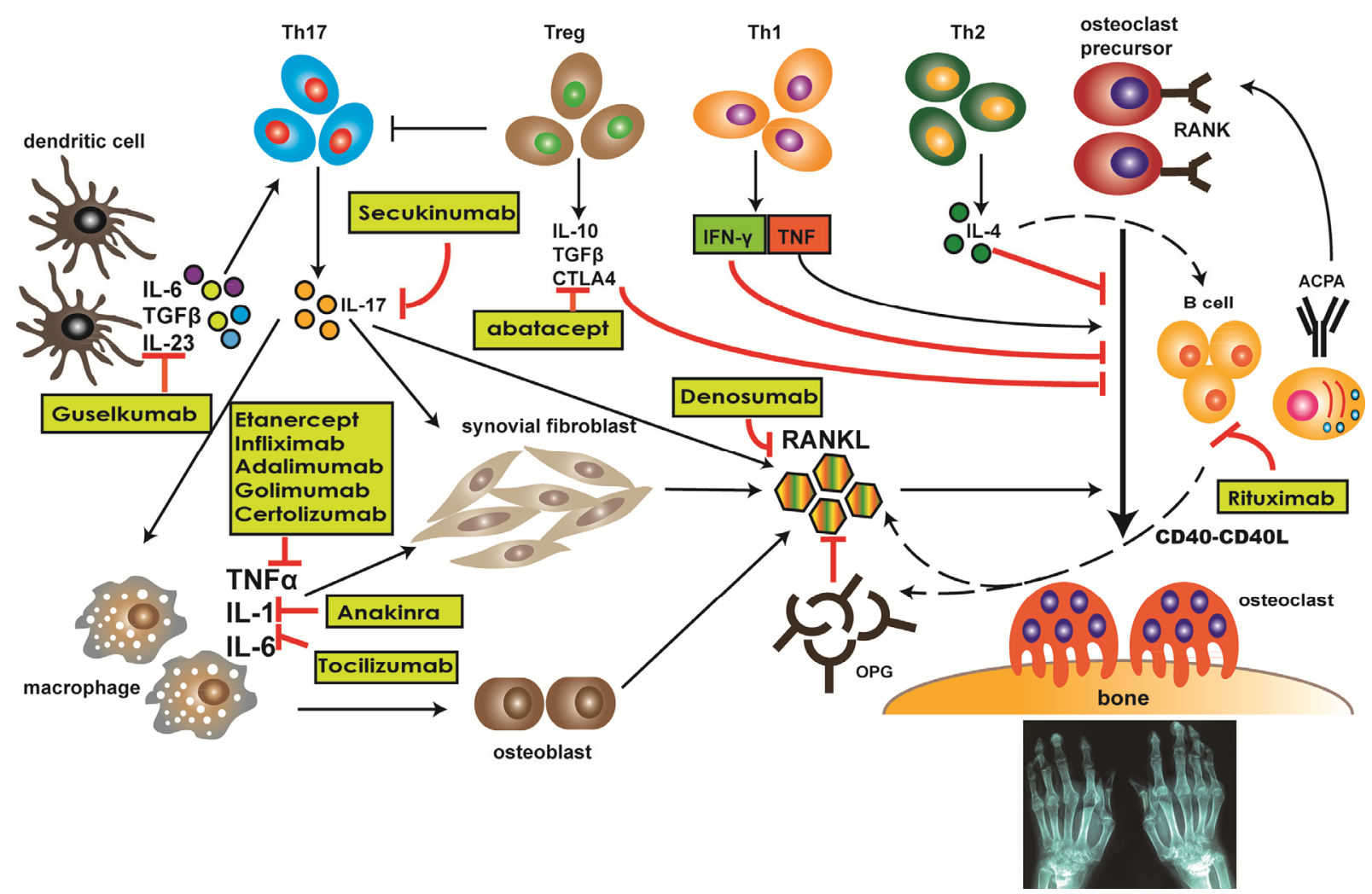

Figure 2 Components of osteoimmunology contribute to bone absorption in RA and target therapy. Immune cells interact with bone cells via cytokines and surface molecules to mediate bone erosion and inflammation-associated bone loss in RA. TNF- $\alpha$, IL- 6 and IL- 1 are the most important pro-inflammatory cytokines in this context, and RANKL is the primary signal in OC differentiation. These recommended therapeutic targets have been confirmed in clinical practice or are waiting for validation in clinical trials. 
with potent suppressive effects on inflammation, but GC exposure is widely known for its adverse effects on bone remodeling, leading to a high risk of vertebral fracture and femur head necrosis. In particular, GCs inhibit bone formation and promote bone resorption to accelerate bone loss, probably by prolonging the survival of OCs and inducing apoptosis of OBs and osteocytes (Mitra, 2011). Further research indicates that GCs can inhibit the Wnt pathway, which is pivotal in OB differentiation, survival and function.

New strategies to improve bone turnover and strengthen bone protection have been employed in OP. Denosumab, which is an antibody against RANKL, is effective in increasing bone mineral density and reducing the bone fracture risk in patients with OP and has been approved for postmenopausal OP treatment. Estrogen and estrogen receptor modulators are also effective in preventing bone loss in postmenopausal women, but adverse effects should be evaluated and monitored. Odanacatib, an inhibitor of cathepsin K, exhibits similar bone protection effects, and approval can be expected soon. Other agents, such as a PTH-related peptide (PTHrp) analog and a Src tyrosine kinase inhibitor, are at the stage of clinical or preclinical evaluations (Makras et al., 2015; Suresh and Abrahamsen, 2015).

\section{SPA (spondyloarthropathy)}

Ankylosing spondylitis (AS) and psoriatic arthritis (PsA) are representative SPA disorders with distinctive osteoclastogenic features. Syndesmophytes and enthesophytes, vertebral bone loss and sacroiliac joint erosion with or without peripheral joint destruction coexist in SPA, indicating disturbed bone remodeling. Enhanced Th17 cell numbers and IL-17 serum levels have also been observed and are believed to be involved in the pathogenesis (Mei et al., 2011; Raychaudhuri et al., 2015; Shen et al., 2009). IL-22 produced by Th17 cells exerts anabolic effects on bone remodeling by stimulating Wnt and BMP signaling and enhancing bone formation (Goldring, 2013). Dickkopf-1 (DKK-1) is a natural inhibitor of Wnt signaling that can induce OPG production and that is devoted to osteoblastogenesis. In contrast to increased DKK-1 in RA, serum DKK-1 in AS has been reported to be decreased and to be inversely correlated with AS disease severity (Yucong et al., 2014). Blockade of DKK-1 in mice induces ankylosis of sacroiliac joints (Uderhardt et al., 2010), indicating that manipulating Wnt signaling may be a promising therapeutic strategy to prevent osteophyte formation at the inflammation site (Schett et al., 2008).

\section{PD (periodontal disease)}

PD is a chronic disease associated with alveolar bone loss and gingival tissue inflammation. Its etiology is an immune reaction to oral bacteria, and especially Porphyromonas gingivalis ( $P$. gingivalis). The compromised periodontium will lose its supportive function, and the affected teeth will ultimately fall out. PD and RA are closely correlated with a high comorbidity and parallel severity (de Pablo et al., 2008; Mercado et al., 2003). Both diseases have common risk factors, such as shared HLA-DRB1 epitope alleles and smoking. $P$. gingivalis is thought to be the major, although not exclusive, cause of PD. The pathogen specifically contributes to protein citrullination, which subsequently stimulates the host immune response and induces autoantigen production, acting as a trigger in the pathological reaction of RA (Lundberg et al., 2010). It has been reported that antibodies to $P$. gingivalis are more commonly observed in RA patients and are significantly correlated with anti-cyclic citrullinated peptide (CCP) titers in RA patients, revealing the inherent connections between the two diseases (Mikuls et al., 2009). What's more, a considerable proportion of Treg-derived IL-17 producing cells (IL- $17^{+}$Foxp $3^{+} \mathrm{T}$ cells) have been found in PD lesions indicating the conversion from Treg to Th17 may play a role in the pathogenesis of PD (Okui et al., 2012).

Periodontal bone loss is associated with increased infiltration of $\mathrm{B}$ cells and $\mathrm{T}$ cells with enhanced RANKL expression and is capable of inducing OC maturation in a RANKL-dependent manner (Kawai et al., 2006). Recently, $\mathrm{Li}$ et al. have found that silencing the Atp6v1c1 gene locally can reduce $\mathrm{OC}$ numbers and reverse bone destruction in PD as well as inhibiting DC and macrophage infiltration and down-regulating pro-inflammatory cytokine production ( $\mathrm{Li}$ et al., 2015). Atp6v1c1 is expressed by OCs and localized on the ruffled border, and it is responsible for encoding a proton pump subunit that is required for OC-mediated extracellular acidification. The acidic milieu is required for solubilization of calcium from bone (Li et al., 1999).

\section{FUTURE PERSPECTIVES}

Advances in osteoimmunology expand and deepen our understanding of the underlying pathophysiological mechanisms in certain osteoarticular disorders and systemic inflammatory diseases. Although the precise mechanisms underlying the intimate communication and regulation involved remain to be elucidated, promising strategies have been developed based on current and growing knowledge in this field. Thinking of the skeletal system and immune system as an integrated unit is paving the way to preventing bone loss and bone destruction, which affect enormous populations. As an osteoclastogenesis inducer, RANKL is theoretically a promising target in osteopenic disease. Denosumab, a human IgG2 monoclonal antibody against RANKL, has been approved to treat postmenopausal OP and bone metastases. A preliminary clinical trial has shown that Denosumab has certain effects in reducing the progression of RA (Cohen et al., 2008). Along with growing understanding of the pathological mechanisms of RA and the 
wide use of TNF-blocking biologics with inspiring effects, knowledge of osteoimmunology is rapidly growing and expanding, and new strategies are emerging.

\section{CONCLUSIONS}

The skeletal system and immune system are closely correlated, and growing knowledge of their interaction and interdependence has given birth to the new interdisciplinary field of osteoimmunology. The RANK/RANKL/OPG triad acts as the central regulator of the crosstalk between the two systems. This triad is not only the pivotal mediator of osteoclastogenesis, leading to bone loss, but also an indispensable factor for LN organogenesis and B cell maturation, in addition to providing potent survival signals for DCs to initiate immune responses. Design of therapeutic approaches should consider these bidirectional effects. Manipulation of the OPG signal or intervention in RANKL expression and the expression of other signaling molecules involved may be promising to ameliorate osteopenic problems in multiple clinical disorders, regardless of their origin.

Compliance and ethics The author(s) declare that they have no conflict of interest.

Acknowledgements This work was supported by the National Natural Science Foundation of China (81550023).

Abu-Amer, Y. (2001). IL-4 abrogates osteoclastogenesis through STAT6dependent inhibition of NF-kappaB. J Clin Invest 107, 1375-1385.

Abu-Amer, Y. (2013). NF-kappaB signaling and bone resorption. Osteoporos Int 24, 2377-2386.

Adamopoulos, I.E., and Bowman, E.P. (2008). Immune regulation of bone loss by Th17 cells. Arthritis Res Ther 10, 225.

Adamopoulos, I.E., Chao, C.C., Geissler, R., Laface, D., Blumenschein, W., Iwakura, Y., McClanahan, T., and Bowman, E.P. (2010). Interleukin-17A upregulates receptor activator of NF-kappaB on osteoclast precursors. Arthritis Res Ther 12, R29.

Akiyama, T., Shimo, Y., Yanai, H., Qin, J., Ohshima, D., Maruyama, Y., Asaumi, Y., Kitazawa, J., Takayanagi, H., Penninger, J.M., Matsumoto, M., Nitta, T., Takahama, Y., and Inoue, J. (2008). The tumor necrosis factor family receptors RANK and CD40 cooperatively establish the thymic medullary microenvironment and self-tolerance. Immunity 29 , 423-437.

Alliston, T., Choy, L., Ducy, P., Karsenty, G., and Derynck, R. (2001). TGF-beta-induced repression of CBFA1 by Smad3 decreases cbfa1 and osteocalcin expression and inhibits osteoblast differentiation. EMBO J 20, 2254-2272.

Alnaeeli, M., Park, J., Mahamed, D., Penninger, J.M., and Teng, Y.T. (2007). Dendritic cells at the osteo-immune interface: implications for inflammation-induced bone loss. J Bone Miner Res 22, 775-780.

Alnaeeli, M., Penninger, J.M., and Teng, Y.T. (2006). Immune interactions with $\mathrm{CD}^{+}{ }^{+} \mathrm{T}$ cells promote the development of functional osteoclasts from murine CD11 $\mathrm{c}^{+}$dendritic cells. J Immunol 177, 3314-3326.

Anderson, D.M., Maraskovsky, E., Billingsley, W.L., Dougall, W.C., Tometsko, M.E., Roux, E.R., Teepe, M.C., DuBose, R.F., Cosman, D., and Galibert, L. (1997). A homologue of the TNF receptor and its ligand enhance T-cell growth and dendritic-cell function. Nature 390, 175-179.

Arboleya, L., and Castaneda, S. (2013). Osteoimmunology: the study of the relationship between the immune system and bone tissue. Reumatol Clin 9, 303-315.

Arron, J.R., and Choi, Y. (2000). Bone versus immune system. Nature 408, 535-536.

Aschenbrenner, K., D’Cruz, L.M., Vollmann, E.H., Hinterberger, M., Emmerich, J., Swee, L.K., Rolink, A., and Klein, L. (2007). Selection of Foxp $3^{+}$regulatory $\mathrm{T}$ cells specific for self antigen expressed and presented by Aire $^{+}$medullary thymic epithelial cells. Nat Immunol 8 , 351-358.

Ashkar, S., Weber, G.F., Panoutsakopoulou, V., Sanchirico, M.E., Jansson, M., Zawaideh, S., Rittling, S.R., Denhardt, D.T., Glimcher, M.J., and Cantor, H. (2000). Eta-1 (osteopontin): an early component of type-1 (cell-mediated) immunity. Science 287, 860-864.

Axmann, R., Herman, S., Zaiss, M., Franz, S., Polzer, K., Zwerina, J., Herrmann, M., Smolen, J., and Schett, G. (2008). CTLA-4 directly inhibits osteoclast formation. Ann Rheum Dis 67, 1603-1609.

Baron, R., Rawadi, G., and Roman-Roman, S. (2006). Wnt signaling: a key regulator of bone mass. Curr Top Dev Biol 76, 103-127.

Bolin, C., Tawara, K., Sutherland, C., Redshaw, J., Aranda, P., Moselhy, J., Anderson, R., and Jorcyk, C.L. (2012). Oncostatin m promotes mammary tumor metastasis to bone and osteolytic bone degradation. Genes Cancer 3, 117-130.

Bucay, N., Sarosi, I., Dunstan, C.R., Morony, S., Tarpley, J., Capparelli, C., Scully, S., Tan, H.L., Xu, W., Lacey, D.L., Boyle, W.J., and Simonet, W.S. (1998). osteoprotegerin-deficient mice develop early onset osteoporosis and arterial calcification. Genes Dev 12, 1260-1268.

Calvi, L.M., Adams, G.B., Weibrecht, K.W., Weber, J.M., Olson, D.P., Knight, M.C., Martin, R.P., Schipani, E., Divieti, P., Bringhurst, F.R., Milner, L.A., Kronenberg, H.M., and Scadden, D.T. (2003). Osteoblastic cells regulate the haematopoietic stem cell niche. Nature 425, 841-846.

Chellaiah, M.A., Kizer, N., Biswas, R., Alvarez, U., Strauss-Schoenberger, J., Rifas, L., Rittling, S.R., Denhardt, D.T., and Hruska, K.A. (2003). Osteopontin deficiency produces osteoclast dysfunction due to reduced CD44 surface expression. Mol Biol Cell 14, 173-189.

Chen, A., Xu, H., Choi, Y., Wang, B., and Zheng, G. (2004). TRANCE counteracts FasL-mediated apoptosis of murine bone marrow-derived dendritic cells. Cell Immunol 231, 40-48.

Chino, T., Draves, K.E., and Clark, E.A. (2009). Regulation of dendritic cell survival and cytokine production by osteoprotegerin. J Leukoc Biol 86, 933-940.

Choi, Y., Woo, K.M., Ko, S.H., Lee, Y.J., Park, S.J., Kim, H.M., and Kwon, B.S. (2001). Osteoclastogenesis is enhanced by activated B cells but suppressed by activated $\mathrm{CD}^{+} \mathrm{T}$ cells. Eur $\mathrm{J}$ Immunol 31, 2179-2188

Cohen, S.B., Dore, R.K., Lane, N.E., Ory, P.A., Peterfy, C.G., Sharp, J.T., van der Heijde, D., Zhou, L., Tsuji, W., Newmark, R., and Denosumab Rheumatoid Arthritis Study, G. (2008). Denosumab treatment effects on structural damage, bone mineral density, and bone turnover in rheumatoid arthritis: a twelve-month, multicenter, randomized, double-blind, placebo-controlled, phase II clinical trial. Arthritis Rheum 58, 1299-1309.

Cutolo, M., Sulli, A., Paolino, S., and Pizzorni, C. (2016). CTLA-4 blockade in the treatment of rheumatoid arthritis: an update. Expert Rev Clin Immunol, 1-9.

Darnay, B.G., Haridas, V., Ni, J., Moore, P.A., and Aggarwal, B.B. (1998). Characterization of the intracellular domain of receptor activator of NF-kappaB (RANK). Interaction with tumor necrosis factor receptor-associated factors and activation of NF-kappab and c-Jun N-terminal kinase. J Biol Chem 273, 20551-20555.

Darnay, B.G., Ni, J., Moore, P.A., and Aggarwal, B.B. (1999). Activation of NF-kappaB by RANK requires tumor necrosis factor receptor-associated factor (TRAF) 6 and NF-kappaB-inducing kinase. Identification of a novel TRAF6 interaction motif. J Biol Chem 274, 7724-7731.

de Pablo, P., Dietrich, T., and McAlindon, T.E. (2008). Association of periodontal disease and tooth loss with rheumatoid arthritis in the US population. J Rheumatol 35, 70-76.

Denhardt, D.T., Giachelli, C.M., and Rittling, S.R. (2001). Role of 
osteopontin in cellular signaling and toxicant injury. Annu Rev Pharmacol Toxicol 41, 723-749.

Despars, G., Pandruvada, S.N., Anginot, A., Domenget, C., Jurdic, P., and Mazzorana, M. (2013). DAP12 overexpression induces osteopenia and impaired early hematopoiesis. PLoS One 8, e65297.

Dhodapkar, K.M., Barbuto, S., Matthews, P., Kukreja, A., Mazumder, A., Vesole, D., Jagannath, S., and Dhodapkar, M.V. (2008). Dendritic cells mediate the induction of polyfunctional human IL17-producing cells (Th17-1 cells) enriched in the bone marrow of patients with myeloma. Blood 112, 2878-2885.

Dohn, U.M., Ostergaard, M., Bird, P., Boonen, A., Johansen, J.S., Moller, J.M., and Hansen, M.S. (2009). Tendency towards erosive regression on magnetic resonance imaging at 12 months in rheumatoid arthritis patients treated with rituximab. Ann Rheum Dis 68, 1072-1073.

Dougall, W.C., Glaccum, M., Charrier, K., Rohrbach, K., Brasel, K., De Smedt, T., Daro, E., Smith, J., Tometsko, M.E., Maliszewski, C.R., Armstrong, A., Shen, V., Bain, S., Cosman, D., Anderson, D., Morrissey, P.J., Peschon, J.J., and Schuh, J. (1999). RANK is essential for osteoclast and lymph node development. Genes Dev 13, 2412-2424.

Dresner-Pollak, R., Gelb, N., Rachmilewitz, D., Karmeli, F., and Weinreb, M. (2004). Interleukin 10-deficient mice develop osteopenia, decreased bone formation, and mechanical fragility of long bones. Gastroenterology 127, 792-801.

Duque, G., Huang, D.C., Dion, N., Macoritto, M., Rivas, D., Li, W., Yang, X.F., Li, J., Lian, J., Marino, F.T., Barralet, J., Lascau, V., Deschenes, C., Ste-Marie, L.G., and Kremer, R. (2011). Interferon-gamma plays a role in bone formation in vivo and rescues osteoporosis in ovariectomized mice. J Bone Miner Res 26, 1472-1483.

Duque, G., Huang, D.C., Macoritto, M., Rivas, D., Yang, X.F., Ste-Marie, L.G., and Kremer, R. (2009). Autocrine regulation of interferon gamma in mesenchymal stem cells plays a role in early osteoblastogenesis. Stem Cells 27, 550-558.

Duy, C., Yu, J.J., Nahar, R., Swaminathan, S., Kweon, S.M., Polo, J.M., Valls, E., Klemm, L., Shojaee, S., Cerchietti, L., Schuh, W., Jack, H.M., Hurtz, C., Ramezani-Rad, P., Herzog, S., Jumaa, H., Koeffler, H.P., de Alboran, I.M., Melnick, A.M., Ye, B.H., and Muschen, M. (2010). BCL6 is critical for the development of a diverse primary B cell repertoire. J Exp Med 207, 1209-1221.

Evans, K.E., and Fox, S.W. (2007). Interleukin-10 inhibits osteoclastogenesis by reducing NFATc1 expression and preventing its translocation to the nucleus. BMC Cell Biol 8, 4.

Felix, R., Cecchini, M.G., and Fleisch, H. (1990a). Macrophage colony stimulating factor restores in vivo bone resorption in the op/op osteopetrotic mouse. Endocrinology 127, 2592-2594.

Felix, R., Cecchini, M.G., Hofstetter, W., Elford, P.R., Stutzer, A., and Fleisch, H. (1990b). Impairment of macrophage colony-stimulating factor production and lack of resident bone marrow macrophages in the osteopetrotic op/op mouse. J Bone Miner Res 5, 781-789.

Franzoso, G., Carlson, L., Xing, L., Poljak, L., Shores, E.W., Brown, K.D., Leonardi, A., Tran, T., Boyce, B.F., and Siebenlist, U. (1997). Requirement for NF-kappaB in osteoclast and B-cell development. Genes Dev 11, 3482-3496.

Fujie, A., Funayama, A., Miyauchi, Y., Sato, Y., Kobayashi, T., Kanagawa, H., Katsuyama, E., Hao, W., Tando, T., Watanabe, R., Morita, M., Miyamoto, K., Kanaji, A., Morioka, H., Matsumoto, M., Toyama, Y., and Miyamoto, T. (2015). Bcl6 promotes osteoblastogenesis through Stat1 inhibition. Biochem Biophys Res Commun 457, 451-456.

Fujikawa, Y., Quinn, J.M., Sabokbar, A., McGee, J.O., and Athanasou, N.A. (1996a). The human osteoclast precursor circulates in the monocyte fraction. Endocrinology 137, 4058-4060.

Fujikawa, Y., Sabokbar, A., Neale, S., and Athanasou, N.A. (1996b). Human osteoclast formation and bone resorption by monocytes and synovial macrophages in rheumatoid arthritis. Ann Rheum Dis 55, 816-822.

Fuller, K., Owens, J.M., Jagger, C.J., Wilson, A., Moss, R., and Chambers, T.J. (1993). Macrophage colony-stimulating factor stimulates survival and chemotactic behavior in isolated osteoclasts. J Exp Med 178,
1733-1744.

Gao, Y., Grassi, F., Ryan, M.R., Terauchi, M., Page, K., Yang, X., Weitzmann, M.N., and Pacifici, R. (2007). IFN-gamma stimulates osteoclast formation and bone loss in vivo via antigen-driven $\mathrm{T}$ cell activation. J Clin Invest 117, 122-132.

Geffroy-Luseau, A., Jego, G., Bataille, R., Campion, L., and Pellat-Deceunynck, C. (2008). Osteoclasts support the survival of human plasma cells in vitro. Int Immunol 20, 775-782.

Goldring, S.R. (2013). Osteoimmunology and bone homeostasis: relevance to spondyloarthritis. Curr Rheumatol Rep 15, 342.

Gravallese, E.M., Manning, C., Tsay, A., Naito, A., Pan, C., Amento, E., and Goldring, S.R. (2000). Synovial tissue in rheumatoid arthritis is a source of osteoclast differentiation factor. Arthritis Rheum 43, 250-258.

Greisen, S.R., Einarsson, H.B., Hvid, M., Hauge, E.M., Deleuran, B., and Kragstrup, T.W. (2015). Spontaneous generation of functional osteoclasts from synovial fluid mononuclear cells as a model of inflammatory osteoclastogenesis. APMIS 123, 779-786.

Guerrini, M.M., Sobacchi, C., Cassani, B., Abinun, M., Kilic, S.S., Pangrazio, A., Moratto, D., Mazzolari, E., Clayton-Smith, J., Orchard, P., Coxon, F.P., Helfrich, M.H., Crockett, J.C., Mellis, D., Vellodi, A., Tezcan, I., Notarangelo, L.D., Rogers, M.J., Vezzoni, P., Villa, A., and Frattini, A. (2008). Human osteoclast-poor osteopetrosis with hypogammaglobulinemia due to TNFRSF11A (RANK) mutations. Am J Hum Genet 83, 64-76.

Hamerman, J.A., Tchao, N.K., Lowell, C.A., and Lanier, L.L. (2005). Enhanced Toll-like receptor responses in the absence of signaling adaptor DAP12. Nat Immunol 6, 579-586.

Harre, U., Georgess, D., Bang, H., Bozec, A., Axmann, R., Ossipova, E., Jakobsson, P.J., Baum, W., Nimmerjahn, F., Szarka, E., Sarmay, G., Krumbholz, G., Neumann, E., Toes, R., Scherer, H.U., Catrina, A.I., Klareskog, L., Jurdic, P., and Schett, G. (2012). Induction of osteoclastogenesis and bone loss by human autoantibodies against citrullinated vimentin. J Clin Invest 122, 1791-1802.

Harre, U., Lang, S.C., Pfeifle, R., Rombouts, Y., Fruhbeisser, S., Amara, K., Bang, H., Lux, A., Koeleman, C.A., Baum, W., Dietel, K., Grohn, F., Malmstrom, V., Klareskog, L., Kronke, G., Kocijan, R., Nimmerjahn, F., Toes, R.E., Herrmann, M., Scherer, H.U., and Schett, G. (2015). Glycosylation of immunoglobulin G determines osteoclast differentiation and bone loss. Nat Commun 6, 6651.

Heinegard, D., Andersson, G., and Reinholt, F.P. (1995). Roles of osteopontin in bone remodeling. Ann N Y Acad Sci 760, 213-222.

Hess, E., Duheron, V., Decossas, M., Lezot, F., Berdal, A., Chea, S., Golub, R., Bosisio, M.R., Bridal, S.L., Choi, Y., Yagita, H., and Mueller, C.G. (2012). RANKL induces organized lymph node growth by stromal cell proliferation. J Immunol 188, 1245-1254.

Hikosaka, Y., Nitta, T., Ohigashi, I., Yano, K., Ishimaru, N., Hayashi, Y., Matsumoto, M., Matsuo, K., Penninger, J.M., Takayanagi, H., Yokota, Y., Yamada, H., Yoshikai, Y., Inoue, J., Akiyama, T., and Takahama, Y. (2008). The cytokine RANKL produced by positively selected thymocytes fosters medullary thymic epithelial cells that express autoimmune regulator. Immunity 29, 438-450.

Horowitz, M.C., Xi, Y., Pflugh, D.L., Hesslein, D.G., Schatz, D.G., Lorenzo, J.A., and Bothwell, A.L. (2004). Pax5-deficient mice exhibit early onset osteopenia with increased osteoclast progenitors. J Immunol $173,6583-6591$.

Horwood, N.J. (2013). Immune cells and bone: coupling goes both ways. Immunol Invest 42, 532-543.

Horwood, N.J., Elliott, J., Martin, T.J., and Gillespie, M.T. (2001). IL-12 alone and in synergy with IL-18 inhibits osteoclast formation in vitro. J Immunol 166, 4915-4921.

Hui, W., Cawston, T.E., Richards, C.D., and Rowan, A.D. (2005). A model of inflammatory arthritis highlights a role for oncostatin $M$ in pro-inflammatory cytokine-induced bone destruction via RANK/RANKL. Arthritis Res Ther 7, R57-R64.

Ignatius, A., Schoengraf, P., Kreja, L., Liedert, A., Recknagel, S., Kandert, S., Brenner, R.E., Schneider, M., Lambris, J.D., and Huber-Lang, M. (2011). Complement C3a and C5a modulate osteoclast formation and inflammatory response of osteoblasts in synergism with IL-1beta. J Cell 
Biochem 112, 2594-2605.

Ikeda, F., Nishimura, R., Matsubara, T., Tanaka, S., Inoue, J., Reddy, S.V., Hata, K., Yamashita, K., Hiraga, T., Watanabe, T., Kukita, T., Yoshioka, K., Rao, A., and Yoneda, T. (2004). Critical roles of c-Jun signaling in regulation of NFAT family and RANKL-regulated osteoclast differentiation. J Clin Invest 114, 475-484.

Ji, J.D., Park-Min, K.H., Shen, Z., Fajardo, R.J., Goldring, S.R., McHugh, K.P., and Ivashkiv, L.B. (2009). Inhibition of RANK expression and osteoclastogenesis by TLRs and IFN-gamma in human osteoclast precursors. J Immunol 183, 7223-7233.

Josien, R., Li, H.L., Ingulli, E., Sarma, S., Wong, B.R., Vologodskaia, M., Steinman, R.M., and Choi, Y. (2000). TRANCE, a tumor necrosis factor family member, enhances the longevity and adjuvant properties of dendritic cells in vivo. J Exp Med 191, 495-502.

Josien, R., Wong, B.R., Li, H.L., Steinman, R.M., and Choi, Y. (1999). TRANCE, a TNF family member, is differentially expressed on T cell subsets and induces cytokine production in dendritic cells. J Immunol $162,2562-2568$.

Jung, Y., Shiozawa, Y., Wang, J., Patel, L.R., Havens, A.M., Song, J., Krebsbach, P.H., Roodman, G.D., and Taichman, R.S. (2011). Annexin-2 is a regulator of stromal cell-derived factor-1/CXCL12 function in the hematopoietic stem cell endosteal niche. Exp Hematol 39, 151-166 e151.

Jung, Y., Wang, J., Song, J., Shiozawa, Y., Wang, J., Havens, A., Wang, Z., Sun, Y.X., Emerson, S.G., Krebsbach, P.H., and Taichman, R.S. (2007). Annexin II expressed by osteoblasts and endothelial cells regulates stem cell adhesion, homing, and engraftment following transplantation. Blood 110, 82-90.

Kang, J.S., Alliston, T., Delston, R., and Derynck, R. (2005). Repression of Runx2 function by TGF-beta through recruitment of class II histone deacetylases by Smad3. EMBO J 24, 2543-2555.

Karsdal, M.A., Henriksen, K., Arnold, M., and Christiansen, C. (2008). Calcitonin: a drug of the past or for the future? Physiologic inhibition of bone resorption while sustaining osteoclast numbers improves bone quality. BioDrugs 22, 137-144.

Kassem, A., Henning, P., Kindlund, B., Lindholm, C., and Lerner, U.H. (2015). TLR5, a novel mediator of innate immunity-induced osteoclastogenesis and bone loss. FASEB J 29, 4449-4460.

Kawai, T., Matsuyama, T., Hosokawa, Y., Makihira, S., Seki, M., Karimbux, N.Y., Goncalves, R.B., Valverde, P., Dibart, S., Li, Y.P., Miranda, L.A., Ernst, C.W., Izumi, Y., and Taubman, M.A. (2006). B and $\mathrm{T}$ lymphocytes are the primary sources of RANKL in the bone resorptive lesion of periodontal disease. Am J Pathol 169, 987-998.

Kelchtermans, H., Geboes, L., Mitera, T., Huskens, D., Leclercq, G., and Matthys, P. (2009). Activated $\mathrm{CD}^{+} \mathrm{CD} 25^{+}$regulatory T cells inhibit osteoclastogenesis and collagen-induced arthritis. Ann Rheum Dis 68, 744-750.

Kim, K.W., Cho, M.L., Lee, S.H., Oh, H.J., Kang, C.M., Ju, J.H., Min, S.Y., Cho, Y.G., Park, S.H., and Kim, H.Y. (2007a). Human rheumatoid synovial fibroblasts promote osteoclastogenic activity by activating RANKL via TLR-2 and TLR-4 activation. Immunol Lett $110,54-64$

Kim, K.W., Cho, M.L., Oh, H.J., Kim, H.R., Kang, C.M., Heo, Y.M., Lee, S.H., and Kim, H.Y. (2009). TLR-3 enhances osteoclastogenesis through upregulation of RANKL expression from fibroblast-like synoviocytes in patients with rheumatoid arthritis. Immunol Lett 124, 9-17.

Kim, N., Odgren, P.R., Kim, D.K., Marks, S.C. Jr., and Choi, Y. (2000). Diverse roles of the tumor necrosis factor family member TRANCE in skeletal physiology revealed by TRANCE deficiency and partial rescue by a lymphocyte-expressed TRANCE transgene. Proc Natl Acad Sci USA 97, 10905-10910.

Kim, Y.G., Lee, C.K., Nah, S.S., Mun, S.H., Yoo, B., and Moon, H.B. (2007b). Human $\mathrm{CD}^{+} \mathrm{CD} 25^{+}$regulatory $\mathrm{T}$ cells inhibit the differentiation of osteoclasts from peripheral blood mononuclear cells. Biochem Biophys Res Commun 357, 1046-1052.

Kobayashi, N., Kadono, Y., Naito, A., Matsumoto, K., Yamamoto, T., Tanaka, S., and Inoue, J. (2001). Segregation of TRAF6-mediated signaling pathways clarifies its role in osteoclastogenesis. EMBO J 20,
$1271-1280$

Kollet, O., Dar, A., Shivtiel, S., Kalinkovich, A., Lapid, K., Sztainberg, Y., Tesio, M., Samstein, R.M., Goichberg, P., Spiegel, A., Elson, A., and Lapidot, T. (2006). Osteoclasts degrade endosteal components and promote mobilization of hematopoietic progenitor cells. Nat Med 12, 657-664.

Komatsu, N., Okamoto, K., Sawa, S., Nakashima, T., Oh-hora, M., Kodama, T., Tanaka, S., Bluestone, J.A., and Takayanagi, H. (2014). Pathogenic conversion of Foxp $3^{+} \mathrm{T}$ cells into $\mathrm{T}_{\mathrm{H}} 17$ cells in autoimmune arthritis. Nat Med 20, 62-68.

Komori, T. (2011). Signaling networks in RUNX2-dependent bone development. J Cell Biochem 112, 750-755.

Kong, Y.Y., Feige, U., Sarosi, I., Bolon, B., Tafuri, A., Morony, S., Capparelli, C., Li, J., Elliott, R., McCabe, S., Wong, T., Campagnuolo, G., Moran, E., Bogoch, E.R., Van, G., Nguyen, L.T., Ohashi, P.S., Lacey, D.L., Fish, E., Boyle, W.J., and Penninger, J.M. (1999a). Activated $\mathrm{T}$ cells regulate bone loss and joint destruction in adjuvant arthritis through osteoprotegerin ligand. Nature 402, 304-309.

Kong, Y.Y., Yoshida, H., Sarosi, I., Tan, H.L., Timms, E., Capparelli, C., Morony, S., Oliveira-dos-Santos, A.J., Van, G., Itie, A., Khoo, W., Wakeham, A., Dunstan, C.R., Lacey, D.L., Mak, T.W., Boyle, W.J., and Penninger, J.M. (1999b). OPGL is a key regulator of osteoclastogenesis, lymphocyte development and lymph-node organogenesis. Nature 397, 315-323.

Koning, J.J., and Mebius, R.E. (2012). Interdependence of stromal and immune cells for lymph node function. Trends Immunol 33, 264-270.

Kotake, S., Udagawa, N., Hakoda, M., Mogi, M., Yano, K., Tsuda, E., Takahashi, K., Furuya, T., Ishiyama, S., Kim, K.J., Saito, S., Nishikawa, T., Takahashi, N., Togari, A., Tomatsu, T., Suda, T., and Kamatani, N. (2001). Activated human $T$ cells directly induce osteoclastogenesis from human monocytes: possible role of T cells in bone destruction in rheumatoid arthritis patients. Arthritis Rheum 44, 1003-1012.

Lacey, D.L., Timms, E., Tan, H.L., Kelley, M.J., Dunstan, C.R., Burgess, T., Elliott, R., Colombero, A., Elliott, G., Scully, S., Hsu, H., Sullivan, J., Hawkins, N., Davy, E., Capparelli, C., Eli, A., Qian, Y.X., Kaufman, S., Sarosi, I., Shalhoub, V., Senaldi, G., Guo, J., Delaney, J., and Boyle, W.J. (1998). Osteoprotegerin ligand is a cytokine that regulates osteoclast differentiation and activation. Cell 93, 165-176.

Le Goff, B., Berthelot, J.M., Maugars, Y., and Heymann, D. (2013). Osteoclasts in RA: diverse origins and functions. Joint Bone Spine 80, 586-591.

Le Goff, B., Singbrant, S., Tonkin, B.A., Martin, T.J., Romas, E., Sims, N.A., and Walsh, N.C. (2014). Oncostatin M acting via OSMR, augments the actions of IL-1 and TNF in synovial fibroblasts. Cytokine $68,101-109$

Lee, K.S., Kim, H.J., Li, Q.L., Chi, X.Z., Ueta, C., Komori, T., Wozney, J.M., Kim, E.G., Choi, J.Y., Ryoo, H.M., and Bae, S.C. (2000). Runx2 is a common target of transforming growth factor betal and bone morphogenetic protein 2, and cooperation between Runx2 and Smad5 induces osteoblast-specific gene expression in the pluripotent mesenchymal precursor cell line C2C12. Mol Cell Biol 20, 8783-8792.

Li, S., Hao, L., Wang, L., Lu, Y., Li, Q., Zhu, Z., Shao, J.Z., and Chen, W. (2015). Targeting Atp6v1c1 prevents inflammation and bone erosion caused by periodontitis and reveals its critical function in osteoimmunology. PLoS One 10, e0134903.

Li, Y., Toraldo, G., Li, A., Yang, X., Zhang, H., Qian, W.P., and Weitzmann, M.N. (2007). B cells and T cells are critical for the preservation of bone homeostasis and attainment of peak bone mass in vivo. Blood 109, 3839-3848.

Li, Y.P., Chen, W., Liang, Y., Li, E., and Stashenko, P. (1999). Atp6i-deficient mice exhibit severe osteopetrosis due to loss of osteoclast-mediated extracellular acidification. Nat Genet 23, 447-451.

Lomaga, M.A., Yeh, W.C., Sarosi, I., Duncan, G.S., Furlonger, C., Ho, A., Morony, S., Capparelli, C., Van, G., Kaufman, S., van der Heiden, A., Itie, A., Wakeham, A., Khoo, W., Sasaki, T., Cao, Z., Penninger, J.M., Paige, C.J., Lacey, D.L., Dunstan, C.R., Boyle, W.J., Goeddel, D.V., and Mak, T.W. (1999). TRAF6 deficiency results in osteopetrosis and defective interleukin-1, CD40, and LPS signaling. Genes Dev 13, 
$1015-1024$.

Lubberts, E., Koenders, M.I., Oppers-Walgreen, B., van den Bersselaar, L., Coenen-de Roo, C.J., Joosten, L.A., and van den Berg, W.B. (2004). Treatment with a neutralizing anti-murine interleukin-17 antibody after the onset of collagen-induced arthritis reduces joint inflammation, cartilage destruction, and bone erosion. Arthritis Rheum 50, 650-659.

Lundberg, K., Wegner, N., Yucel-Lindberg, T., and Venables, P.J. (2010). Periodontitis in RA-the citrullinated enolase connection. Nat Rev Rheumatol 6, 727-730.

Makras, P., Delaroudis, S., and Anastasilakis, A.D. (2015). Novel therapies for osteoporosis. Metabolism 64, 1199-1214.

Manilay, J.O., and Zouali, M. (2014). Tight relationships between B lymphocytes and the skeletal system. Trends Mol Med 20, 405-412.

Marino, S., Logan, J.G., Mellis, D., and Capulli, M. (2014). Generation and culture of osteoclasts. Bonekey Rep 3, 570.

Marrella, V., Lo Iacono, N., Fontana, E., Sobacchi, C., Sic, H., Schena, F., Sereni, L., Castiello, M.C., Poliani, P.L., Vezzoni, P., Cassani, B., Traggiai, E., and Villa, A. (2015). IL-10 critically modulates B cell responsiveness in $\mathrm{Rankl}^{-1-}$ mice. J Immunol 194, 4144-4153.

Maruyama, K., Takada, Y., Ray, N., Kishimoto, Y., Penninger, J.M., Yasuda, H., and Matsuo, K. (2006). Receptor activator of NF-kappa B ligand and osteoprotegerin regulate proinflammatory cytokine production in mice. J Immunol 177, 3799-3805.

Matsuoka, K., Park, K.A., Ito, M., Ikeda, K., and Takeshita, S. (2014). Osteoclast-derived complement component 3a stimulates osteoblast differentiation. J Bone Miner Res 29, 1522-1530.

McCarthy, N.I., Cowan, J.E., Nakamura, K., Bacon, A., Baik, S., White, A.J., Parnell, S.M., Jenkinson, E.J., Jenkinson, W.E., and Anderson, G. (2015). Osteoprotegerin-mediated homeostasis of $\mathrm{Rank}^{+}$thymic epithelial cells does not limit Foxp $3^{+}$regulatory T cell development. J Immunol 195, 2675-2682.

McInnes, I.B., and Schett, G. (2007). Cytokines in the pathogenesis of rheumatoid arthritis. Nat Rev Immunol 7, 429-442.

McKercher, S.R., Henkel, G.W., and Maki, R.A. (1999). The transcription factor PU.1 does not regulate lineage commitment but has lineage-specific effects. J Leukoc Biol 66, 727-732.

McKercher, S.R., Torbett, B.E., Anderson, K.L., Henkel, G.W., Vestal, D.J., Baribault, H., Klemsz, M., Feeney, A.J., Wu, G.E., Paige, C.J., and Maki, R.A. (1996). Targeted disruption of the PU.1 gene results in multiple hematopoietic abnormalities. EMBO J 15, 5647-5658.

Mei, Y., Pan, F., Gao, J., Ge, R., Duan, Z., Zeng, Z., Liao, F., Xia, G., Wang, S., Xu, S., Xu, J., Zhang, L., and Ye, D. (2011). Increased serum IL-17 and IL-23 in the patient with ankylosing spondylitis. Clin Rheumatol 30, 269-273.

Mercado, F.B., Marshall, R.I., and Bartold, P.M. (2003). Inter-relationships between rheumatoid arthritis and periodontal disease. A review. J Clin Periodontol 30, 761-772.

Mikuls, T.R., Payne, J.B., Reinhardt, R.A., Thiele, G.M., Maziarz, E., Cannella, A.C., Holers, V.M., Kuhn, K.A., and O'Dell, J.R. (2009). Antibody responses to Porphyromonas gingivalis ( $P$. gingivalis) in subjects with rheumatoid arthritis and periodontitis. Int Immunopharmacol 9, 38-42.

Mitra, R. (2011). Adverse effects of corticosteroids on bone metabolism: a review. PM R 3, 466-471; quiz 471.

Miyamoto, K., Yoshida, S., Kawasumi, M., Hashimoto, K., Kimura, T., Sato, Y., Kobayashi, T., Miyauchi, Y., Hoshi, H., Iwasaki, R., Miyamoto, H., Hao, W., Morioka, H., Chiba, K., Kobayashi, T., Yasuda, H., Penninger, J.M., Toyama, Y., Suda, T., and Miyamoto, T. (2011). Osteoclasts are dispensable for hematopoietic stem cell maintenance and mobilization. J Exp Med 208, 2175-2181.

Miyauchi, Y., Ninomiya, K., Miyamoto, H., Sakamoto, A., Iwasaki, R., Hoshi, H., Miyamoto, K., Hao, W., Yoshida, S., Morioka, H., Chiba, K., Kato, S., Tokuhisa, T., Saitou, M., Toyama, Y., Suda, T., and Miyamoto, T. (2010). The Blimp1-Bcl6 axis is critical to regulate osteoclast differentiation and bone homeostasis. J Exp Med 207, 751-762.

Mizuno, A., Amizuka, N., Irie, K., Murakami, A., Fujise, N., Kanno, T., Sato, Y., Nakagawa, N., Yasuda, H., Mochizuki, S., Gomibuchi, T.,
Yano, K., Shima, N., Washida, N., Tsuda, E., Morinaga, T., Higashio, K., and Ozawa, H. (1998). Severe osteoporosis in mice lacking osteoclastogenesis inhibitory factor/osteoprotegerin. Biochem Biophys Res Commun 247, 610-615.

Mohamed, S.G., Sugiyama, E., Shinoda, K., Taki, H., Hounoki, H., Abdel-Aziz, H.O., Maruyama, M., Kobayashi, M., Ogawa, H., and Miyahara, T. (2007). Interleukin-10 inhibits RANKL-mediated expression of NFATc1 in part via suppression of c-Fos and c-Jun in RAW264.7 cells and mouse bone marrow cells. Bone 41, 592-602.

Moreno, J.L., Kaczmarek, M., Keegan, A.D., and Tondravi, M. (2003). IL-4 suppresses osteoclast development and mature osteoclast function by a STAT6-dependent mechanism: irreversible inhibition of the differentiation program activated by RANKL. Blood 102, 1078-1086.

Mueller, C.G., and Hess, E. (2012). Emerging Functions of RANKL in Lymphoid Tissues. Front Immunol 3, 261.

Nakae, S., Nambu, A., Sudo, K., and Iwakura, Y. (2003). Suppression of immune induction of collagen-induced arthritis in IL-17-deficient mice. J Immunol 171, 6173-6177.

Nakagawa, N., Kinosaki, M., Yamaguchi, K., Shima, N., Yasuda, H., Yano, K., Morinaga, T., and Higashio, K. (1998). RANK is the essential signaling receptor for osteoclast differentiation factor in osteoclastogenesis. Biochem Biophys Res Commun 253, 395-400.

Nam, D., Mau, E., Wang, Y., Wright, D., Silkstone, D., Whetstone, H., Whyne, C., and Alman, B. (2012). T-lymphocytes enable osteoblast maturation via IL-17F during the early phase of fracture repair. PLoS One 7, e40044.

Negishi-Koga, T., Gober, H.J., Sumiya, E., Komatsu, N., Okamoto, K., Sawa, S., Suematsu, A., Suda, T., Sato, K., Takai, T., and Takayanagi, H. (2015). Immune complexes regulate bone metabolism through FcRgamma signalling. Nat Commun 6, 6637.

Nie, H., Zheng, Y., Li, R., Guo, T.B., He, D., Fang, L., Liu, X., Xiao, L., Chen, X., Wan, B., Chin, Y.E., and Zhang, J.Z. (2013). Phosphorylation of FOXP3 controls regulatory $\mathrm{T}$ cell function and is inhibited by TNF-alpha in rheumatoid arthritis. Nat Med 19, 322-328.

Nilsson, S.K., Johnston, H.M., Whitty, G.A., Williams, B., Webb, R.J., Denhardt, D.T., Bertoncello, I., Bendall, L.J., Simmons, P.J., and Haylock, D.N. (2005). Osteopontin, a key component of the hematopoietic stem cell niche and regulator of primitive hematopoietic progenitor cells. Blood 106, 1232-1239.

Nutt, S.L., Heavey, B., Rolink, A.G., and Busslinger, M. (1999). Commitment to the B-lymphoid lineage depends on the transcription factor Pax5. Nature 401, 556-562.

Odgren, P.R., Kim, N., MacKay, C.A., Mason-Savas, A., Choi, Y., and Marks, S.C. Jr. (2003). The role of RANKL (TRANCE/TNFSF11), a tumor necrosis factor family member, in skeletal development: effects of gene knockout and transgenic rescue. Connect Tissue Res 44, 264-271.

Ohigashi, I., Nitta, T., Lkhagvasuren, E., Yasuda, H., and Takahama, Y. (2011). Effects of RANKL on the thymic medulla. Eur J Immunol 41, 1822-1827.

Ohtsuji, M., Lin, Q., Nishikawa, K., Ohtsuji, N., Okazaki, H., Tsurui, H., Amano, H., Shirai, T., Nishimoto, N., Nishimura, H., and Hirose, S. (2015). IL-6 signal blockade ameliorates the enhanced osteoclastogenesis and the associated joint destruction in a novel FcgammaRIIB-deficient rheumatoid arthritis mouse model. Mod Rheumatol 25, 270-277.

Okada, S., Wang, Z.Q., Grigoriadis, A.E., Wagner, E.F., and von Ruden, T. (1994). Mice lacking c-fos have normal hematopoietic stem cells but exhibit altered B-cell differentiation due to an impaired bone marrow environment. Mol Cell Biol 14, 382-390.

Okui, T., Aoki, Y., Ito, H., Honda, T., and Yamazaki, K. (2012). The presence of $\mathrm{IL}^{-17^{+}} / \mathrm{FOXP}^{+}$double-positive cells in periodontitis. $\mathrm{J}$ Dent Res 91, 574-579.

Page, G., and Miossec, P. (2005). RANK and RANKL expression as markers of dendritic cell-T cell interactions in paired samples of rheumatoid synovium and lymph nodes. Arthritis Rheum 52, 2307-2312.

Palmqvist, P., Lundberg, P., Persson, E., Johansson, A., Lundgren, I., Lie, A., Conaway, H.H., and Lerner, U.H. (2006). Inhibition of hormone 
and cytokine-stimulated osteoclastogenesis and bone resorption by interleukin-4 and interleukin-13 is associated with increased osteoprotegerin and decreased RANKL and RANK in a STAT6-dependent pathway. J Biol Chem 281, 2414-2429.

Pappalardo, A., and Thompson, K. (2013). Activated gammadelta T cells inhibit osteoclast differentiation and resorptive activity in vitro. Clin Exp Immunol 174, 281-291.

Pappalardo, A., and Thompson, K. (2015). Novel immunostimulatory effects of osteoclasts and macrophages on human gammadelta $\mathrm{T}$ cells. Bone 71, 180-188.

Pathak, J.L., Bravenboer, N., Verschueren, P., Lems, W.F., Luyten, F.P., Klein-Nulend, J., and Bakker, A.D. (2014). Inflammatory factors in the circulation of patients with active rheumatoid arthritis stimulate osteoclastogenesis via endogenous cytokine production by osteoblasts. Osteoporos Int 25, 2453-2463.

Qin, L., Raggatt, L.J., and Partridge, N.C. (2004). Parathyroid hormone: a double-edged sword for bone metabolism. Trends Endocrinol Metab $15,60-65$.

Raychaudhuri, S.K., Saxena, A., and Raychaudhuri, S.P. (2015). Role of IL-17 in the pathogenesis of psoriatic arthritis and axial spondyloarthritis. Clin Rheumatol 34, 1019-1023.

Rifas, L., Arackal, S., and Weitzmann, M.N. (2003). Inflammatory T cells rapidly induce differentiation of human bone marrow stromal cells into mature osteoblasts. J Cell Biochem 88, 650-659.

Rittling, S.R., and Singh, R. (2015). Osteopontin in Immune-mediated Diseases. J Dent Res 94, 1638-1645.

Rivollier, A., Mazzorana, M., Tebib, J., Piperno, M., Aitsiselmi, T., Rabourdin-Combe, C., Jurdic, P., and Servet-Delprat, C. (2004). Immature dendritic cell transdifferentiation into osteoclasts: a novel pathway sustained by the rheumatoid arthritis microenvironment. Blood 104, 4029-4037.

Roozendaal, R., and Mebius, R.E. (2011). Stromal cell-immune cell interactions. Annu Rev Immunol 29, 23-43.

Santiago-Schwarz, F., Anand, P., Liu, S., and Carsons, S.E. (2001). Dendritic cells (DCs) in rheumatoid arthritis (RA): progenitor cells and soluble factors contained in RA synovial fluid yield a subset of myeloid DCs that preferentially activate Th1 inflammatory-type responses. J Immunol 167, 1758-1768.

Sato, K., Suematsu, A., Okamoto, K., Yamaguchi, A., Morishita, Y., Kadono, Y., Tanaka, S., Kodama, T., Akira, S., Iwakura, Y., Cua, D.J., and Takayanagi, H. (2006). Th17 functions as an osteoclastogenic helper T cell subset that links T cell activation and bone destruction. J Exp Med 203, 2673-2682.

Schett, G., Zwerina, J., and David, J.P. (2008). The role of Wnt proteins in arthritis. Nat Clin Pract Rheumatol 4, 473-480.

Schiff, M. (2011). Abatacept treatment for rheumatoid arthritis. Rheumatology (Oxford) 50, 437-449.

Shen, H., Goodall, J.C., and Hill Gaston, J.S. (2009). Frequency and phenotype of peripheral blood Th17 cells in ankylosing spondylitis and rheumatoid arthritis. Arthritis Rheum 60, 1647-1656.

Simonet, W.S., Lacey, D.L., Dunstan, C.R., Kelley, M., Chang, M.S., Luthy, R., Nguyen, H.Q., Wooden, S., Bennett, L., Boone, T., Shimamoto, G., DeRose, M., Elliott, R., Colombero, A., Tan, H.L., Trail, G., Sullivan, J., Davy, E., Bucay, N., Renshaw-Gegg, L., Hughes, T.M., Hill, D., Pattison, W., Campbell, P., Sander, S., Van, G., Tarpley, J., Derby, P., Lee, R., and Boyle, W.J. (1997). Osteoprotegerin: a novel secreted protein involved in the regulation of bone density. Cell 89, 309-319.

Sobacchi, C., Frattini, A., Guerrini, M.M., Abinun, M., Pangrazio, A., Susani, L., Bredius, R., Mancini, G., Cant, A., Bishop, N., Grabowski, P., Del Fattore, A., Messina, C., Errigo, G., Coxon, F.P., Scott, D.I., Teti, A., Rogers, M.J., Vezzoni, P., Villa, A., and Helfrich, M.H. (2007). Osteoclast-poor human osteopetrosis due to mutations in the gene encoding RANKL. Nat Genet 39, 960-962.

Stolina, M., Dwyer, D., Ominsky, M.S., Corbin, T., Van, G., Bolon, B., Sarosi, I., McCabe, J., Zack, D.J., and Kostenuik, P. (2007). Continuous RANKL inhibition in osteoprotegerin transgenic mice and rats suppresses bone resorption without impairing lymphorganogenesis or functional immune responses. J Immunol 179, 7497-7505.
Sugiyama, T., and Nagasawa, T. (2012). Bone marrow niches for hematopoietic stem cells and immune cells. Inflamm Allergy Drug Targets 11, 201-206.

Suresh, E., and Abrahamsen, B. (2015). Denosumab: a novel antiresorptive drug for osteoporosis. Cleve Clin J Med 82, 105-114.

Takayanagi, H. (2005). Mechanistic insight into osteoclast differentiation in osteoimmunology. J Mol Med (Berl) 83, 170-179.

Takayanagi, H. (2007). The role of NFAT in osteoclast formation. Ann N Y Acad Sci 1116, 227-237.

Takayanagi, H. (2009). Osteoimmunology and the effects of the immune system on bone. Nat Rev Rheumatol 5, 667-676.

Takayanagi, H., Oda, H., Yamamoto, S., Kawaguchi, H., Tanaka, S., Nishikawa, T., and Koshihara, Y. (1997). A new mechanism of bone destruction in rheumatoid arthritis: synovial fibroblasts induce osteoclastogenesis. Biochem Biophys Res Commun 240, 279-286.

Takayanagi, H., Ogasawara, K., Hida, S., Chiba, T., Murata, S., Sato, K., Takaoka, A., Yokochi, T., Oda, H., Tanaka, K., Nakamura, K., and Taniguchi, T. (2000). T-cell-mediated regulation of osteoclastogenesis by signalling cross-talk between RANKL and IFN-gamma. Nature 408, 600-605.

Theill, L.E., Boyle, W.J., and Penninger, J.M. (2002). RANK-L and RANK: T cells, bone loss, and mammalian evolution. Annu Rev Immunol 20, 795-823.

Tondravi, M.M., McKercher, S.R., Anderson, K., Erdmann, J.M., Quiroz, M., Maki, R., and Teitelbaum, S.L. (1997). Osteopetrosis in mice lacking haematopoietic transcription factor PU.1. Nature 386, 81-84.

Tu, Z., Bu, H., Dennis, J.E., and Lin, F. (2010). Efficient osteoclast differentiation requires local complement activation. Blood 116, 4456-4463.

Uderhardt, S., Diarra, D., Katzenbeisser, J., David, J.P., Zwerina, J., Richards, W., Kronke, G., and Schett, G. (2010). Blockade of Dickkopf (DKK)-1 induces fusion of sacroiliac joints. Ann Rheum Dis 69, 592-597.

Wagner, E.F., and Eferl, R. (2005). Fos/AP-1 proteins in bone and the immune system. Immunol Rev 208, 126-140.

Wang, Z.Q., Ovitt, C., Grigoriadis, A.E., Mohle-Steinlein, U., Ruther, U., and Wagner, E.F. (1992). Bone and haematopoietic defects in mice lacking c-fos. Nature 360, 741-745.

Wei, S., Kitaura, H., Zhou, P., Ross, F.P., and Teitelbaum, S.L. (2005). IL-1 mediates TNF-induced osteoclastogenesis. J Clin Invest 115, 282-290.

Wong, B.R., Besser, D., Kim, N., Arron, J.R., Vologodskaia, M., Hanafusa, H., and Choi, Y. (1999a). TRANCE, a TNF family member, activates Akt/PKB through a signaling complex involving TRAF6 and c-Src. Mol Cell 4, 1041-1049.

Wong, B.R., Josien, R., and Choi, Y. (1999b). TRANCE is a TNF family member that regulates dendritic cell and osteoclast function. J Leukoc Biol 65, 715-724.

Wong, B.R., Josien, R., Lee, S.Y., Sauter, B., Li, H.L., Steinman, R.M., and Choi, Y. (1997a). TRANCE (tumor necrosis factor [TNF]-related activation-induced cytokine), a new TNF family member predominantly expressed in T cells, is a dendritic cell-specific survival factor. J Exp Med 186, 2075-2080.

Wong, B.R., Rho, J., Arron, J., Robinson, E., Orlinick, J., Chao, M., Kalachikov, S., Cayani, E., Bartlett, F.S., 3rd, Frankel, W.N., Lee, S.Y., and Choi, Y. (1997b). TRANCE is a novel ligand of the tumor necrosis factor receptor family that activates c-Jun $\mathrm{N}$-terminal kinase in $\mathrm{T}$ cells. J Biol Chem 272, 25190-25194.

Woodward, J. (2010). Regulation of haematopoietic progenitor cell proliferation and survival: the involvement of the osteoblast. Cell Adh Migr 4, 4-6.

Wu, J.Y., Purton, L.E., Rodda, S.J., Chen, M., Weinstein, L.S., McMahon, A.P., Scadden, D.T., and Kronenberg, H.M. (2008). Osteoblastic regulation of $\mathrm{B}$ lymphopoiesis is mediated by Gs\{alpha\}-dependent signaling pathways. Proc Natl Acad Sci USA 105, 16976-16981.

Xiong, J., Piemontese, M., Onal, M., Campbell, J., Goellner, J.J., Dusevich, V., Bonewald, L., Manolagas, S.C., and O'Brien, C.A. (2015). Osteocytes, not osteoblasts or lining cells, are the main source of the RANKL required for osteoclast formation in remodeling bone. 
PLoS One 10, e0138189.

Xu, G., Nie, H., Li, N., Zheng, W., Zhang, D., Feng, G., Ni, L., Xu, R., Hong, J., and Zhang, J.Z. (2005). Role of osteopontin in amplification and perpetuation of rheumatoid synovitis. J Clin Invest 115, $1060-1067$.

Yamada, A., Takami, M., Kawawa, T., Yasuhara, R., Zhao, B., Mochizuki, A., Miyamoto, Y., Eto, T., Yasuda, H., Nakamichi, Y., Kim, N., Katagiri, T., Suda, T., and Kamijo, R. (2007). Interleukin-4 inhibition of osteoclast differentiation is stronger than that of interleukin-13 and they are equivalent for induction of osteoprotegerin production from osteoblasts. Immunology 120, 573-579.

Yamashita, Y., Ukai, T., Nakamura, H., Yoshinaga, Y., Kobayashi, H., Takamori, Y., Noguchi, S., Yoshimura, A., and Hara, Y. (2015). RANKL pretreatment plays an important role in the differentiation of pit-forming osteoclasts induced by TNF-alpha on murine bone marrow macrophages. Arch Oral Biol 60, 1273-1282.

Yasuda, H., Shima, N., Nakagawa, N., Yamaguchi, K., Kinosaki, M., Mochizuki, S., Tomoyasu, A., Yano, K., Goto, M., Murakami, A., Tsuda, E., Morinaga, T., Higashio, K., Udagawa, N., Takahashi, N., and Suda, T. (1998). Osteoclast differentiation factor is a ligand for osteoprotegerin/osteoclastogenesis-inhibitory factor and is identical to TRANCE/RANKL. Proc Natl Acad Sci USA 95, 3597-3602.

Yoshida, T., and Stern, P.H. (2012). How vitamin D works on bone. Endocrinol Metab Clin North Am 41, 557-569.

Yucong, Z., Lu, L., Shengfa, L., Yongliang, Y., Ruguo, S., and Yikai, L. (2014). Serum functional dickkopf-1 levels are inversely correlated with radiographic severity of ankylosing spondylitis. Clin Lab 60, $1527-1531$

Yun, T.J., Chaudhary, P.M., Shu, G.L., Frazer, J.K., Ewings, M.K., Schwartz, S.M., Pascual, V., Hood, L.E., and Clark, E.A. (1998). OPG/FDCR-1, a TNF receptor family member, is expressed in lymphoid cells and is up-regulated by ligating CD40. J Immunol 161,
6113-6121.

Yun, T.J., Tallquist, M.D., Aicher, A., Rafferty, K.L., Marshall, A.J., Moon, J.J., Ewings, M.E., Mohaupt, M., Herring, S.W., and Clark, E.A. (2001). Osteoprotegerin, a crucial regulator of bone metabolism, also regulates B cell development and function. J Immunol 166, 1482-1491.

Zaiss, M.M., Axmann, R., Zwerina, J., Polzer, K., Guckel, E., Skapenko, A., Schulze-Koops, H., Horwood, N., Cope, A., and Schett, G. (2007). Treg cells suppress osteoclast formation: a new link between the immune system and bone. Arthritis Rheum 56, 4104-4112.

Zaiss, M.M., Frey, B., Hess, A., Zwerina, J., Luther, J., Nimmerjahn, F., Engelke, K., Kollias, G., Hunig, T., Schett, G., and David, J.P. (2010a). Regulatory $\mathrm{T}$ cells protect from local and systemic bone destruction in arthritis. J Immunol 184, 7238-7246.

Zaiss, M.M., Sarter, K., Hess, A., Engelke, K., Bohm, C., Nimmerjahn, F., Voll, R., Schett, G., and David, J.P. (2010b). Increased bone density and resistance to ovariectomy-induced bone loss in FoxP3-transgenic mice based on impaired osteoclast differentiation. Arthritis Rheum 62, $2328-2338$.

Zhang, J., Niu, C., Ye, L., Huang, H., He, X., Tong, W.G., Ross, J., Haug, J., Johnson, T., Feng, J.Q., Harris, S., Wiedemann, L.M., Mishina, Y., and Li, L. (2003). Identification of the haematopoietic stem cell niche and control of the niche size. Nature 425, 836-841.

Zhang, Y.H., Heulsmann, A., Tondravi, M.M., Mukherjee, A., and Abu-Amer, Y. (2001). Tumor necrosis factor-alpha (TNF) stimulates RANKL-induced osteoclastogenesis via coupling of TNF type 1 receptor and RANK signaling pathways. J Biol Chem 276, 563-568.

Zhu, J., Garrett, R., Jung, Y., Zhang, Y., Kim, N., Wang, J., Joe, G.J., Hexner, E., Choi, Y., Taichman, R.S., and Emerson, S.G. (2007). Osteoblasts support B-lymphocyte commitment and differentiation from hematopoietic stem cells. Blood 109, 3706-3712.

Zipfel, P.F., and Skerka, C. (2009). Complement regulators and inhibitory proteins. Nat Rev Immunol 9, 729-740.

Open Access This article is distributed under the terms of the Creative Commons Attribution License which permits any use, distribution, and reproduction in any medium, provided the original author(s) and source are credited. 